\title{
Article \\ Metabolomic Reprogramming of C57BL/6-Macrophages during Early Infection with L. amazonensis
}

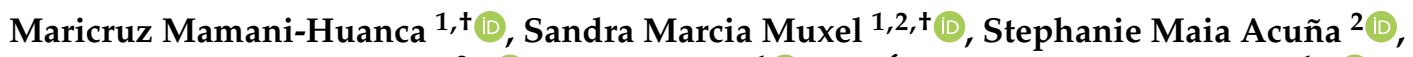 \\ Lucile Maria Floeter-Winter ${ }^{2, *(\mathbb{D})}$, Coral Barbas ${ }^{1}$ (D) and Ángeles López-Gonzálvez ${ }^{1, *(D)}$ \\ 1 Centre for Metabolomics and Bioanalysis (CEMBIO), Department of Chemistry and Biochemistry, \\ Facultad de Farmacia, Universidad San Pablo-CEU, CEU Universities, Urbanización Montepríncipe, \\ Boadilla del Monte, 28660 Madrid, Spain; mar.mamani.ce@ceindo.ceu.es (M.M.-H.); \\ sandrammuxel@usp.br (S.M.M.); cbarbas@ceu.es (C.B.) \\ 2 Departamento de Fisiologia, Instituto de Biociências, Universidade de São Paulo, Rua do Matão, Travessa 14, \\ 101, São Paulo CEP-05508-090, SP, Brazil; stephanie.acuna@usp.br \\ * Correspondence: lucile@ib.usp.br (L.M.F.-W.); alopgon@ceu.es (Á.L.-G.); Tel.: +55-(11)-3091 (L.M.F.-W.); \\ +34-91-3724769 (Á.L.-G.) \\ $+\quad$ These authors contributed equally to this work.
}

check for updates

Citation: Mamani-Huanca, M.; Muxel, S.M.; Acuña, S.M.;

Floeter-Winter, L.M.; Barbas, C.; López-Gonzálvez, Á. Metabolomic Reprogramming of C57BL/6-Macrophages during Early Infection with L. amazonensis. Int. J. Mol. Sci. 2021, 22, 6883. https:// doi.org/10.3390/ijms22136883

Academic Editor: Rustam I. Aminov

Received: 17 May 2021

Accepted: 23 June 2021

Published: 26 June 2021

Publisher's Note: MDPI stays neutral with regard to jurisdictional claims in published maps and institutional affiliations.

Copyright: (c) 2021 by the authors. Licensee MDPI, Basel, Switzerland. This article is an open access article distributed under the terms and conditions of the Creative Commons Attribution (CC BY) license (https:/ / creativecommons.org/licenses/by/ $4.0 /)$.

\begin{abstract}
Leishmania survival inside macrophages depends on factors that lead to the immune response evasion during the infection. In this context, the metabolic scenario of the host cell-parasite relationship can be crucial to understanding how this parasite can survive inside host cells due to the host's metabolic pathways reprogramming. In this work, we aimed to analyze metabolic networks of bone marrow-derived macrophages from C57BL/6 mice infected with Leishmania amazonensis wild type $(\mathrm{La}-\mathrm{WT})$ or arginase knocked out $\left(\mathrm{La}-\mathrm{arg}^{-}\right)$, using the untargeted Capillary ElectrophoresisMass Spectrometry (CE-MS) approach to assess metabolomic profile. Macrophages showed specific changes in metabolite abundance upon Leishmania infection, as well as in the absence of parasitearginase. The absence of L. amazonensis-arginase promoted the regulation of both host and parasite urea cycle, glycine and serine metabolism, ammonia recycling, metabolism of arginine, proline, aspartate, glutamate, spermidine, spermine, methylhistidine, and glutathione metabolism. The increased L-arginine, L-citrulline, L-glutamine, oxidized glutathione, S-adenosylmethionine, $\mathrm{N}$ acetylspermidine, trypanothione disulfide, and trypanothione levels were observed in La-WT-infected C57BL/6-macrophage compared to uninfected. The absence of parasite arginase increased L-arginine, argininic acid, and citrulline levels and reduced ornithine, putrescine, S-adenosylmethionine, glutamic acid, proline, $N$-glutamyl-alanine, glutamyl-arginine, trypanothione disulfide, and trypanothione when compared to La-WT infected macrophage. Moreover, the absence of parasite arginase leads to an increase in NO production levels and a higher infectivity rate at $4 \mathrm{~h}$ of infection. The data presented here show a host-dependent regulation of metabolomic profiles of C57BL/ 6 macrophages compared to the previously observed BALB/c macrophages infected with L. amazonensis, an important fact due to the dual and contrasting macrophage phenotypes of those mice. In addition, the Leishmania-arginase showed interference with the urea cycle, glycine, and glutathione metabolism during host-pathogen interactions.
\end{abstract}

Keywords: polyamines pathway; metabolites; bone marrow-derived macrophages; arginase; nitric oxide synthase

\section{Introduction}

Macrophages are a heterogeneous population of cells that can acquire distinct functional phenotypes in response to cytokines or microbial antigens, playing a critical role in innate and adaptative immune responses [1,2]. Macrophages have a broad spectrum of functional phenotypes, classically represented by two extreme polarizations, pro-inflammatory M1 macrophages presenting microbicidal activity and anti-inflammatory M2 macrophages 
with activity in tissue repair, wound healing, and in response against parasitic infections [3]. M1 macrophages are induced by recognition of microbial antigens, such as lipopolysaccharide (LPS) and lipophosphoglycan (LPG), via pattern recognition receptors (PRRs) as Toll-like receptors (TLRs) and by pro-inflammatory cytokines as interferon-gamma (IFN- $\gamma$ ) and tumor necrosis factor-alpha (TNF- $\alpha$ ) [4-6]. They can also be characterized by the expression of nitric oxide synthase 2 (NOS2), producing microbicidal agent nitric oxide (NO) from L-arginine. The production of these free radical blocks, commonly the oxidative phosphorylation (OXPHOS), leads to a glycolytic phenotype upon the ATP production [7-9]. Additionally, the NOS2 activity is dependent on four co-factors, the cytosolic NADPH being the first [10]. To support the NO production, M1 macrophages present a high flux through the pentose phosphate pathway (PPP), generating the necessary NADPH [11-13]. They also show an increase in particular tricarboxylic cycle (TCA cycle) metabolites such as citrate, succinate, and itaconate $[14,15]$. Moreover, M2 macrophages express arginase-1 (ARG1) which uses arginine to increase ornithine, a substrate to polyamines production (putrescine, spermidine, and spermine). These molecules are used by cells to proliferate, synthesize collagen, and promote tissue remodeling $[16,17]$. In a metabolic approach, M2 macrophages have enhanced OXPHOS and fatty acid oxidation [7-9]; sometimes, they can appear foamy, being strongly related to the severity of atherosclerosis to the accumulation of cholesterol $[18,19]$.

A combination of stimuli usually determines macrophages phenotypes. They can recognize many pathogens, such as Leishmania amazonensis, an intracellular parasite transmitted to mammals via the bite of a sand fly vector. The infection caused by this protozoan leads to tegumentary leishmaniasis in humans [20,21]. On the other hand, during the early phase of mice macrophage infection, the parasite promotes a modulation in hostgene expression, distinctly in BALB/c and C57BL/6, implicating in the metabolism of arginine and, consequently, implicating balance in M1/M2 macrophages during in vitro infection [22-24]. BALB/c-macrophages are more susceptible to late in vitro infection than C57BL/6-macrophages, but infectivity in the early phase is similar [22-24]. Additionally, in vivo infections show that BALB/c mice are susceptible to L. amazonensis infection, presenting severe cutaneous lesions, whereas C57BL/ 6 mice present a moderate lesion size $[25,26]$.

The L-arginine metabolism balances the macrophages leishmanicidal activity and parasite survival [24,27-30]. Leishmania arginase enzyme is essential for parasite survival and infectivity [31]. Promastigote forms of L. amazonensis knockout for arginase ( $\left(\mathrm{a}-\mathrm{arg}^{-}\right)$ present a change in the metabolite content as a result of the absence of the enzyme, increasing the proline and glutamate levels to supply ornithine and putrescine, indicating that arginase activity is important to parasite survival [31-33]. Lower levels of ornithine and putrescine contrasting with higher arginine and citrulline levels are present promastigotes of $L a$-arg ${ }^{-}$compared to L. amazonensis wild-type ( $\left.L a-W T\right)$. The arginase from the parasite competes to arginine inside the macrophage, interfering in the gene expression and metabolism of host cells $[34,35]$. The modulation of arginine transporters can control the arginine availability on parasite and host cells [36-40].

The metabolome profile of BALB/c-macrophages indicated that the L-arginine metabolism favors polyamines production [24]. Here, we explore the metabolome fingerprint of C57BL/6-macrophages during early infection with L. amazonensis, using untargeted Capillary Electrophoresis-Mass Spectrometry (CE-MS) approach. The L. amazonensis infection alters the mix of host and parasite metabolites from the urea cycle, glycine, and serine metabolism, ammonia recycling, arginine metabolism, proline, aspartate, glutamate, spermidine, histidine, and glutathione metabolism. The absence of parasite arginase implicates in the increased levels of arginine, $\mathrm{NO}$, polyamines production, glutathione and trypanothione, and parasite arginase function on macrophage metabolism. 


\section{Results}

2.1. The Parasite Arginase Modulates NO Production and Infectivity in Leishmania-Infected Macrophages

The infectivity of $L a-\mathrm{WT}$ or $L a-\mathrm{arg}^{-}$in C57BL/6 macrophages were analysed after $4,24,48$, or $72 \mathrm{~h}$ of infection. The frequency of infected macrophages, the number of amastigotes per infected macrophages, and index of infection (rate of infected macrophages multiplied by the number of amastigotes per infected macrophages) were performed in image flow cytometry. The frequency of infected macrophages was reduced in C57BL/6- $\mathrm{La}_{\text {- } \mathrm{arg}^{-}}(90.46 \% \pm 0.60)$ compared to C57BL/6-La-WT $(95.20 \% \pm 0.19)$ at $4 \mathrm{~h}$ of infection, but the number of amastigotes per infected macrophages was increased in C57BL/6-La-arg ${ }^{-}(2.79 \pm 0.06)$ compared to C57Bl/ $6-\mathrm{La}-\mathrm{WT}(2.07 \pm 0.01)$ at $4 \mathrm{~h}$ of infection (Figure $1 \mathrm{~A}-\mathrm{C}$ ). Additionally, after 24 and $48 \mathrm{~h}$ of infection, the number of amastigotes per infected macrophages was higher in C57BL/6-La-arg ${ }^{-}$than C57BL/6-La-WT, but showed a time-coursed stabilization. Consequently, the infection index was higher in C57BL/6- $\mathrm{La}$ $\arg ^{-}$than to C57BL/6-La-WT at 4, 24, and $48 \mathrm{~h}$ of infection (Supplementary Figure S1). See Supplementary Figure S2 for details of Infectivity Analysis Gate Strategy.
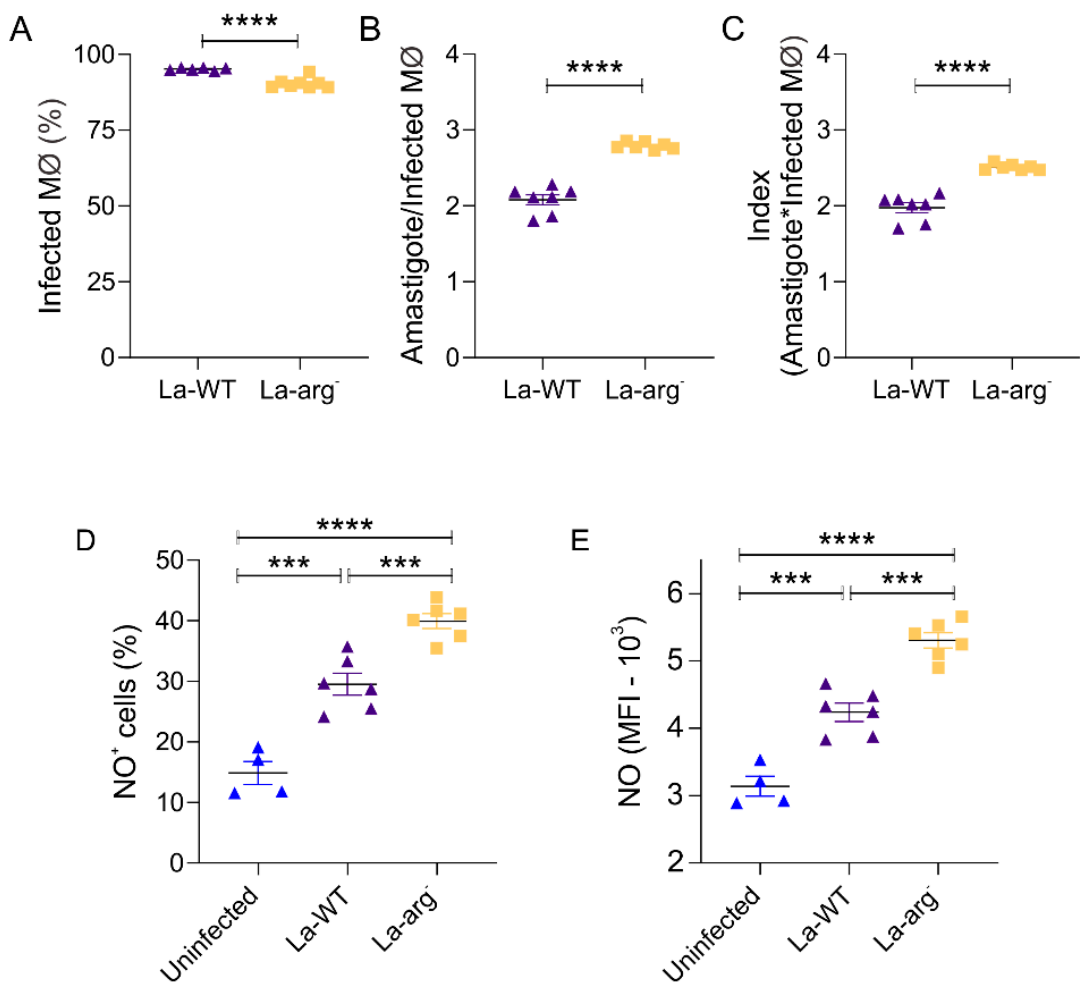

Figure 1. Infection index and NO production in C57BL/ 6 macrophages infected with L. amazonensis La-WT or $L a$-arg- . (A) C57BL/6-macrophages $\left(5 \times 10^{5}\right)$ were infected with CFSE-labelled L. amazonensis wild type (purple triangle) or with L. amazonensis arginase knockout (yellow square) (MOI5:1) and collected after $4 \mathrm{~h}$ for analysis of infectivity by image flow cytometer, gating in the CFSE-internalized cells to count the frequency of infected macrophages (infected MØ). (B) Spot count tool to determine the number of infected MØ. (C) Index of infection was calculated by multiplying the rate of infected MØ by the number of amastigotes per infected MØ. (D) C57BL/6-macrophages $\left(5 \times 10^{5}\right)$ were infected with L. amazonensis wild type (purple triangle) or with L. amazonensis arginase knockout (yellow square) (MOI5:1), and after $4 \mathrm{~h}$ were labeled with $5 \mu \mathrm{M}$ of DAF-FM for NO quantification in image flow cytometry, gating in DAF-FM+ cell quantify the frequency of NO producing cells $\left(\mathrm{NO}^{+}\right.$cells). (E) Media of fluorescence intensity (MFI). The values were compared to the non-infected macrophages (blue triangle). Each point represents the individual values $(\mathrm{n}=6) .\left({ }^{* * *}\right) p$-value $<0.01$; $\left.{ }^{* * * *}\right) p$-value $<0.001$. 
To evaluate the ability of C57BL/6 macrophages infected with L. amazonensis to produce $\mathrm{NO}$ and the impact of parasite arginase, macrophages uninfected and infected for $4 \mathrm{~h}$ with $L$. amazonensis $L a$-WT or with $L a$-arg ${ }^{-}$were labeled with DAF-FM ${ }^{+}$, and the frequency of DAF-FM ${ }^{+}$cells and MFI were analyzed in image flow cytometry (Figure 1D,E). After $4 \mathrm{~h}$, the frequency of cells producing NO and MFI in C57BL/6-La-WT was increased 1.98-times and 1.35-times, respectively, in relation to those uninfected. Additionally, in the infection with $\mathrm{La}$-arg ${ }^{-}$, the frequency of cells producing $\mathrm{NO}$ increased by 2.68 -times, and MFI 1.69-times, in relation to uninfected. The frequency of cells producing NO was 1.35times, and MFI was 1.25 high in C57BL/6-La-arg ${ }^{-}$compared with C57BL/6-La-WT. These data indicated a differential NO-production regulation during infection with L. amazonensis influenced by parasite arginase activity. See Supplementary Figure S3 for details of NO Quantification Gates Strategy.

\subsection{Statistical Analyses of the Metabolic Profile of Leishmania Infected C57BL/6-Macrophages}

Three groups of samples from C57BL/6 macrophages infected with L. amazonensis $(\mathrm{La}-\mathrm{WT})(\mathrm{n}=9), \mathrm{C} 57 \mathrm{BL} / 6$ macrophages infected with L. amazonensis knockout for arginase $\left(\mathrm{L} a-\mathrm{arg}^{-}\right)(\mathrm{n}=10)$, and uninfected C57BL/6 macrophages $(\mathrm{n}=10)$ were used for the untargeted metabolomics CE-MS approach.

As a result of sample analysis and data processing, a total of 269 features were obtained after the deconvolution. The quality of the analysis was evaluated along with the experiment by observing the quality control $(\mathrm{QC})$ clustering in the unsupervised PCA-X plot model (Supplementary Figure S4). PCA-X plot model showed $R^{2}=0.991$ indicating good quality of sample analysis. The model was also built to analyze PLS-DA discrimination. The clustering of the three different groups is observed, indicating that the metabolites' levels have changed due to the macrophages' infection. These differences were evaluated by an OPLS-DA model, concerning the quality of the multivariate models obtained; all the models presented good quality, presenting $R^{2} \geq 0.957$ and $Q^{2} \geq 0.947$ values (Figure 2). Confidence intervals of Jack-Knife, correlation $p$ ( $p$ corr) $>|0.5|$, and variables importance in projection (VIP) $>1$ were calculated to identify the features that are statistically significant in the multivariate (MVA) statistics (Supplementary Table S1).

The univariate analysis (UVA) statistics results using non-parametric one-way ANOVA (Kruskal-Wallis test) showed a greater number of significant variables. Consequently, pairs of groups were compared, and those with a $p<0.05$ were considered significant metabolites using the Mann-Whitney $U$ test. These features were annotated by monosotopic mass and relative migration time (RMT) using an in-house library available at CEUMassMediator (CE-MS search), an online open-source tool developed in our laboratory (http:/ / ceumass.eps.uspceu.es/index_cesearch.xhtml) (May 2021) [41]. Fifty-three metabolites were found to be statistically significant, revealing the modulation of infection. Fiftytwo metabolites appeared to be modulated in La-WT-infected compared to non-infected macrophages, indicating that infection with L. amazonensis results in an increased abundance of metabolites mediated by its metabolism within macrophages and/or manipulate the metabolism of the host. Forty-seven metabolites appeared modified in macrophages infected with $L a-\mathrm{arg}^{-}$compared to the non-infected ones, as a result of the metabolism of the parasite in the host cell and the activation of microbicides mechanisms in macrophages (Supplementary Table S1). To observe parasite arginase activity inside the host cell, the La-arg ${ }^{-}$and $L a-W T$-infected C57BL/6-macrophages were compared (Table 1), revealing 34 modulated metabolites. 

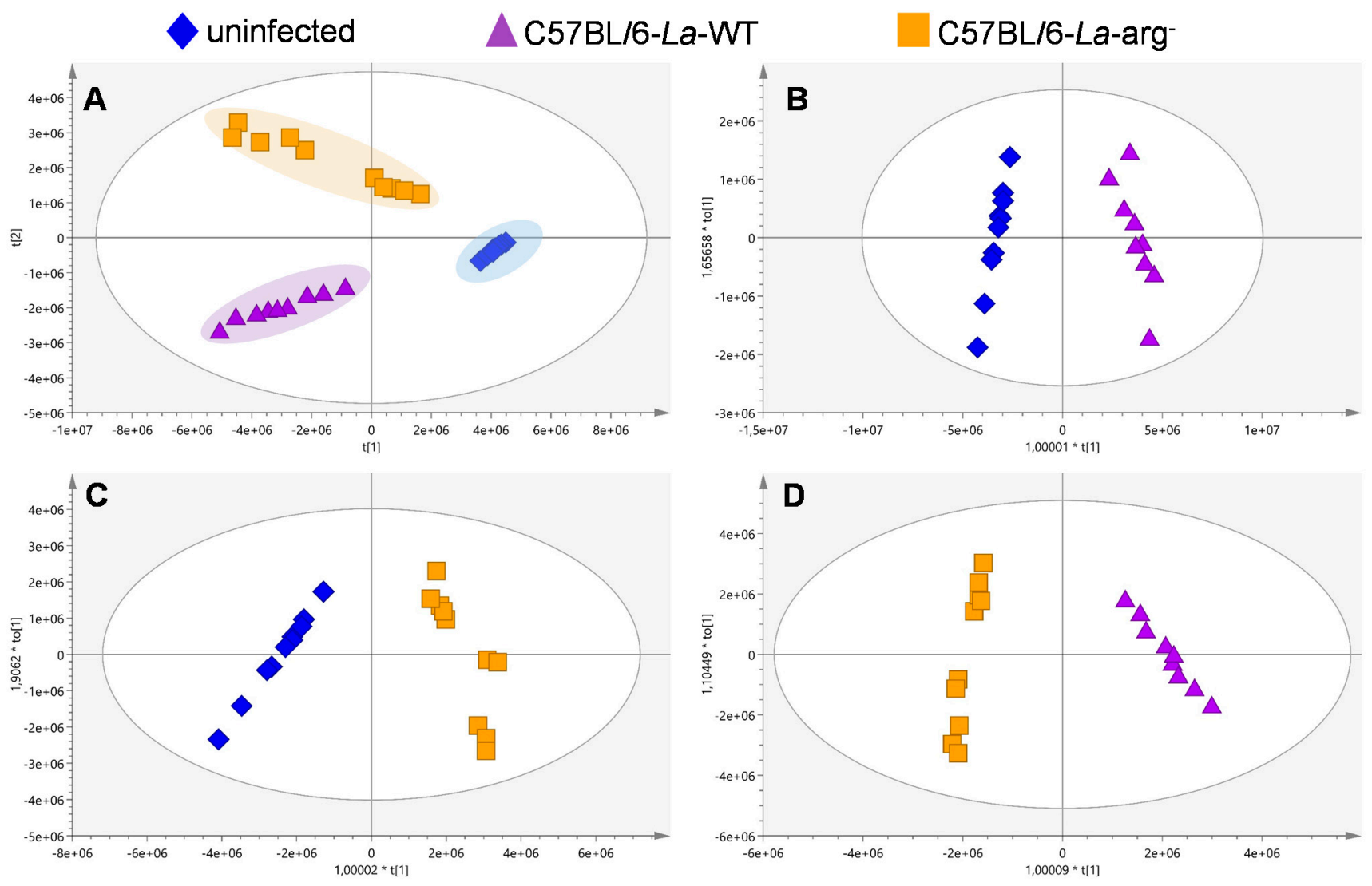

Figure 2. Partial least squares discriminant analysis (PLS-DA) and Orthogonal partial least-squares-discriminant analysis (OPLS-DA) analysis of variation between the two groups of L. amazonensis infected C57BL/6-macrophages. (A) Score plots for the PLS-DA and model were built to compare three conditions: C57BL/6- $\mathrm{La}$-arg ${ }^{-}$infected macrophage, C57BL/6- $\mathrm{Ca}-$ WT infected macrophage, and uninfected macrophage $\left(\mathrm{R}^{2}=0.957\right.$ and $\left.\mathrm{Q}^{2}=0.934\right)$. OPLS-DA model was built for the comparison; (B) C57BL/6-La-WT infected macrophage vs. uninfected macrophage $\left(\mathrm{R}^{2}=0.975\right.$ and $\left.\mathrm{Q}^{2}=0.965\right)$; (C) C57BL/6$L a$-arg ${ }^{-}$-infected macrophage vs. uninfected macrophage $\left(\mathrm{R}^{2}=0.914\right.$ and $\left.\mathrm{Q}^{2}=0.901\right)$; and (D) C57BL/6-La-arg ${ }^{-}$infected macrophage vs. C57BL/6-La-WT infected macrophage $\left(\mathrm{R}^{2}=0.957\right.$ and $\left.\mathrm{Q}^{2}=0.947\right)$.

2.3. Parasite Arginase Activity Leads to Differential Metabolites Profiles of C57BL/6-Macrophages Infected with L. amazonensis

The overview of the untargeted metabolome of $L a$-WT-infected macrophages or La$\mathrm{arg}^{-}$-infected macrophages compared to uninfected macrophages showed an increased level of arginine, argininic acid, citrulline, arginosuccinic acid, ornithine, putrescine, $N$ acetylspermidine, S-adenosylmethionine, oxidized glutathione, trypanothione disulfide, proline, glutamine, and glutamic acid, as observed by their percentage change in Table S1 and intensity of peak area of each metabolite in Figures $3 \mathrm{C}$ and 4 . The variations of the predictors correlated and orthogonal to each group's response were evaluated in Figure 2B,C. 


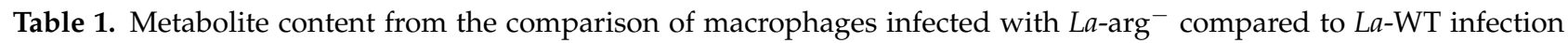
extracted from the one-way ANOVA comparison among these two groups plus the uninfected.

\begin{tabular}{|c|c|c|c|c|c|c|c|c|c|}
\hline Name & Mass (Da) & RMT & $\%$ RSD (QC) & $p$-Value ${ }^{\text {(a) }}$ & $p$ FDR & $p$-Value ${ }^{(\mathbf{b})}$ & $\%$ Change & $p$ (corr) & VIP \\
\hline Glycine & 75.0330 & 0.72 & 8.24 & $4.47 \times 10^{-6}$ & $2.23 \mathrm{E}-05$ & $4.33 \times 10^{-5}$ & -41.30 & -0.84 & $<1$ \\
\hline Putrescine & 88.1000 & 0.42 & 5.81 & $3.92 \times 10^{-6}$ & 2.07E-05 & $2.17 \times 10^{-5}$ & -58.46 & -0.80 & $<1$ \\
\hline Alanine & 89.0483 & 0.77 & 7.31 & $1.85 \times 10^{-5}$ & $4.74 \mathrm{E}-05$ & $1.01 \times 10^{-2}$ & -24.82 & -0.62 & 2.81 \\
\hline 4-aminobutanoic acid & 103.0647 & 0.67 & 7.41 & $1.85 \times 10^{-5}$ & $4.74 \mathrm{E}-05$ & $1.01 \times 10^{-2}$ & 57.39 & 0.57 & $<1$ \\
\hline Serine & 105.0429 & 0.85 & 6.10 & $7.46 \times 10^{-6}$ & $2.76 \mathrm{E}-05$ & $2.60 \times 10^{4}$ & -37.88 & -0.79 & $<1$ \\
\hline Proline & 115.0634 & 0.92 & 7.42 & $5.14 \times 10^{-6}$ & $2.34 \mathrm{E}-05$ & $2.17 \times 10^{-5}$ & -73.83 & -0.96 & 1.73 \\
\hline Valine & 117.0792 & 0.85 & 6.73 & $1.26 \times 10^{-5}$ & 3.70E-05 & $2.99 \times 10^{3}$ & -30.00 & -0.69 & 2.06 \\
\hline Pipecolic acid & 129.0789 & 0.87 & 6.71 & $4.98 \times 10^{-6}$ & 2.34E-05 & $6.50 \times 10^{4}$ & 117.06 & 0.67 & 4.05 \\
\hline Isoleucine/leucine & 131.0945 & 0.87 & 6.51 & $3.92 \times 10^{-6}$ & 2.07E-05 & $2.17 \times 10^{-5}$ & -56.42 & -0.91 & 4.16 \\
\hline Asparagine & 132.0528 & 0.89 & 6.82 & $5.74 \times 10^{-6}$ & $2.50 \mathrm{E}-05$ & $1.52 \times 10^{4}$ & -41.67 & -0.78 & $<1$ \\
\hline Ornithine & 132.0896 & 0.60 & 6.67 & $1.04 \times 10^{-2}$ & $1.80 \mathrm{E}-04$ & $2.17 \times 10^{-5}$ & -92.47 & -0.99 & 2.00 \\
\hline Aspartic acid & 133.0374 & 0.97 & 6.46 & $2.10 \times 10^{-2}$ & 2.88E-02 & $1.72 \times 10^{-2}$ & -19.58 & -0.56 & $<1$ \\
\hline Hypoxanthine & 136.0385 & 1.01 & 5.95 & $1.69 \times 10^{-5}$ & $4.56 \mathrm{E}-05$ & $7.62 \times 10^{3}$ & -26.98 & -0.61 & $<1$ \\
\hline Glutamic acid & 147.0532 & 0.92 & 5.46 & $6.34 \times 10^{-5}$ & 1.17E-04 & $4.14 \times 10^{3}$ & -26.26 & -0.66 & 3.45 \\
\hline Methionine & 149.0512 & 0.91 & 3.94 & $1.13 \times 10^{-5}$ & $3.54 \mathrm{E}-05$ & $2.10 \times 10^{3}$ & -34.19 & -0.75 & $<1$ \\
\hline Xanthine & 152.0271 & 1.72 & 12.19 & $1.53 \times 10^{-2}$ & $2.15 \mathrm{E}-02$ & $2.79 \times 10^{-2}$ & 19.21 & 0.50 & $<1$ \\
\hline Histidine & 155.0696 & 0.64 & 6.61 & $3.92 \times 10^{-6}$ & 2.07E-05 & $2.17 \times 10^{-5}$ & -59.90 & -0.93 & 1.96 \\
\hline Imidazolelactic acid & 156.0554 & 0.76 & 8.51 & $1.06 \times 10^{-5}$ & 3.41E-05 & $7.62 \times 10^{-3}$ & -27.91 & -0.61 & $<1$ \\
\hline Phenylalanine & 165.0808 & 0.93 & 6.50 & $8.17 \times 10^{-6}$ & 2.92E-05 & $6.50 \times 10^{-4}$ & -36.86 & -0.75 & 1.05 \\
\hline 1-Methylhistidine & 169.0856 & 0.66 & 10.42 & $2.32 \times 10^{-6}$ & $1.77 \mathrm{E}-05$ & $2.17 \times 10^{-5}$ & -81.52 & -0.98 & $<1$ \\
\hline Arginine & 174.1117 & 0.63 & 6.37 & $9.14 \times 10^{-6}$ & $3.05 \mathrm{E}-05$ & $9.74 \times 10^{-4}$ & 100.48 & 0.66 & 3.77 \\
\hline Citrulline & 175.0972 & 0.94 & 6.14 & $2.32 \times 10^{-6}$ & 1.77E-05 & $2.17 \times 10^{-5}$ & 220.70 & 0.82 & $<1$ \\
\hline Argininic acid & 175.0975 & 0.79 & 5.67 & $2.32 \times 10^{-6}$ & 1.77E-05 & $2.17 \times 10^{-5}$ & 1919.49 & 0.86 & $<1$ \\
\hline Tyrosine & 181.0739 & 0.96 & 5.81 & $1.26 \times 10^{-5}$ & 3.70E-05 & $2.99 \times 10^{-3}$ & -37.73 & -0.78 & $<1$ \\
\hline Tryptophan & 204.0894 & 0.93 & 5.11 & $1.54 \times 10^{-6}$ & $1.77 \mathrm{E}-05$ & $2.17 \times 10^{-5}$ & -27.53 & -0.70 & $<1$ \\
\hline$N$-carbamyl-arginine ${ }^{(\mathrm{c})}$ & 217.1191 & 0.84 & 22.26 & $2.65 \times 10^{-6}$ & 1.77E-05 & $4.33 \times 10^{-5}$ & $L a-\mathrm{WT}^{(\mathrm{d})}$ & $<0.5$ & $<1$ \\
\hline$N$-glutamyl-alanine ${ }^{(\mathrm{c})}$ & 218.0906 & 1.03 & 7.04 & $2.32 \times 10^{-6}$ & 1.77E-05 & $2.17 \times 10^{-5}$ & -51.06 & -0.86 & $<1$ \\
\hline Cystathionine & 222.0679 & 0.85 & 4.06 & $6.61 \times 10^{-6}$ & 2.64E-05 & $1.52 \times 10^{-4}$ & -57.72 & -0.93 & $<1$ \\
\hline Neuraminic acid ${ }^{(c)}$ & 267.0961 & 1.13 & 7.88 & $2.65 \times 10^{-6}$ & $1.77 \mathrm{E}-05$ & $4.33 \times 10^{-5}$ & -40.89 & -0.79 & $<1$ \\
\hline $\begin{array}{l}N-(1-\text { Deoxy-1-fructosyl) } \\
\text { threonine }^{(\mathrm{c})}\end{array}$ & 281.1118 & 1.13 & 7.78 & $9.14 \times 10^{-6}$ & $3.05 \mathrm{E}-05$ & $9.74 \times 10^{-4}$ & -44.93 & -0.86 & $<1$ \\
\hline Glutamylarginine $^{(\mathrm{c})}$ & 303.1550 & 0.76 & 9.35 & $6.27 \times 10^{-6}$ & 2.61E-05 & $1.45 \times 10^{-3}$ & $L a-\mathrm{WT}^{(\mathrm{d})}$ & $<0.5$ & $<1$ \\
\hline S-Adenosylmethionine ${ }^{(c)}$ & 398.1385 & 0.63 & 4.84 & $2.65 \times 10^{-6}$ & $1.71 \mathrm{E}-05$ & $4.33 \times 10^{-5}$ & -33.16 & -0.74 & $<1$ \\
\hline Trypanothione disulfide & 721.2896 & 0.82 & 25.13 & $3.92 \times 10^{-6}$ & 2.07E-05 & $2.17 \times 10^{-5}$ & -35.56 & -0.71 & $<1$ \\
\hline Trypanothione & 723.3057 & 0.84 & 25.12 & $1.85 \times 10^{-5}$ & $4.74 \mathrm{E}-05$ & $1.01 \times 10^{-2}$ & -52.10 & -0.80 & $<1$ \\
\hline
\end{tabular}

(a) ANOVA $p$-values Kruskal Wallis test, ${ }^{(b)} p$-values Mann-Whitney U test, ${ }^{(c)}$ tentative identification using only monoisotopic mass, and

(d) metabolite present only in La-WT group. RMT: Relative migration time.

Focusing on investigating the parasite arginase impacts on the metabolism of infected macrophages, we compared the levels of metabolites from $L a$-arg ${ }^{-}$-infected macrophages versus La-WT-infected macrophages (Table 1 and Figures 3 and 4). Based on metabolites from L-arginine metabolism, the absence of parasite arginase upregulated arginine, citrulline, and argininic acid levels. On the other hand, it downregulated the levels of putrescine, proline, ornithine, glutamic acid, S-adenosylmethionine, cystathionine, $\mathrm{N}$ carbamyl- arginine, trypanothione disulfide, and trypanothione.

Furthermore, heatmap analysis of the magnitude, directionality, and significance for the association of the 53 differentially modulated metabolites showed the clustering of $L a$-arg ${ }^{-}$-infected macrophages and La-WT-infected macrophages in a distinct way of uninfected macrophages (Figure 5). 

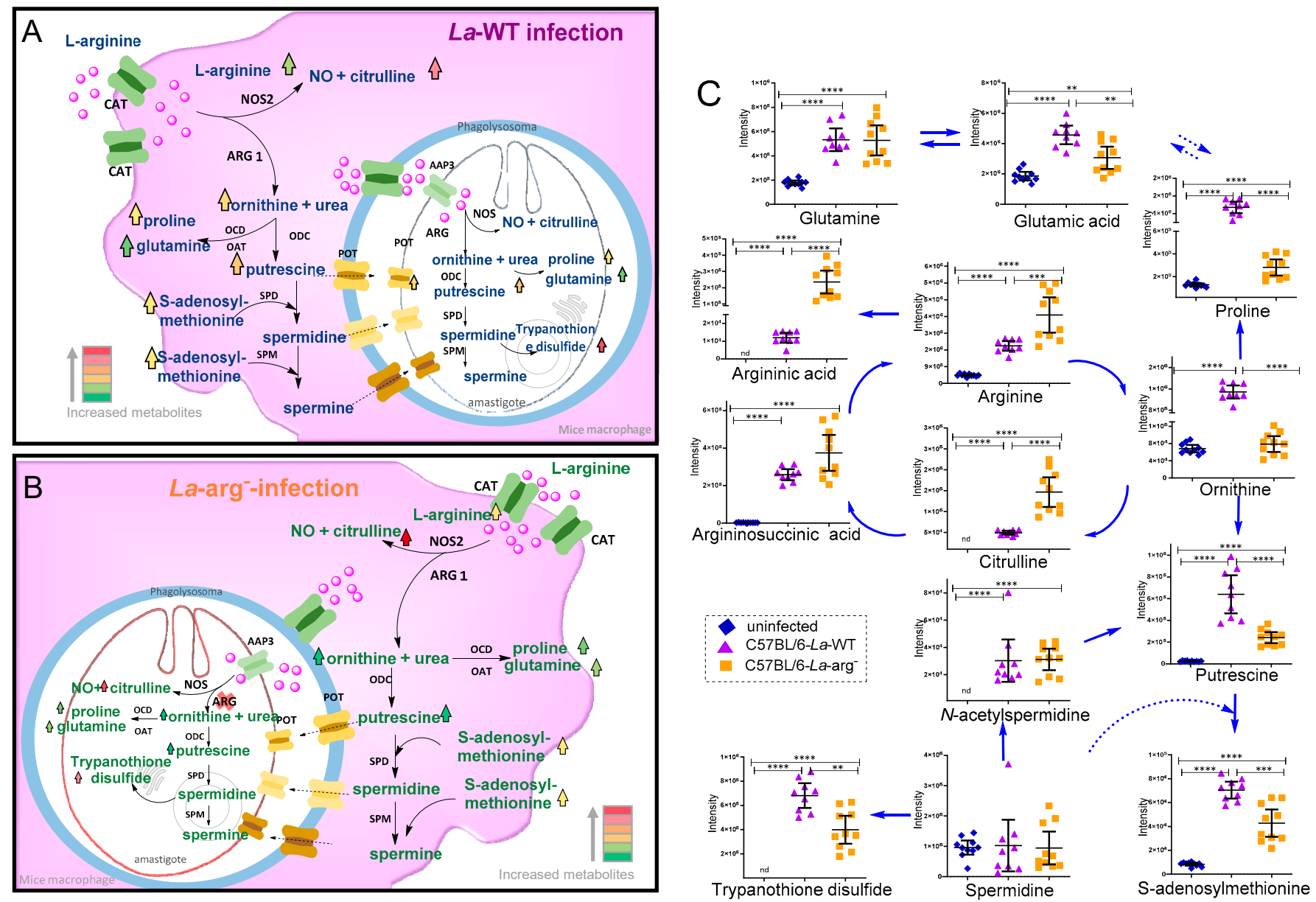

Figure 3. Schematic representation of L-arginine metabolism in Leishmania-infected macrophages. (A) L. amazonensis WT infection can increase the levels of L-arginine via uptake by cationic amino acid transporter (CAT) in macrophage, and via amino acid permease 3 (AAP3) in amastigote form of Leishmania. L-arginine can be converted by host nitric oxide synthase 2 in nitric oxide and citrulline, as seen at its increased levels, leading a leishmanicidal activity or parasite-NOS, regulating amastigote survival and replication. On the other hand, host arginase 1 (ARG1) and parasite arginase (ARG) competes by arginine to produce ornithine and subsequently in polyamines: putrescine via ornithine decarboxylase (ODC), which is used to produce spermidine via spermidine synthase (SPD) and subsequently used by spermine synthase (SPM) to produce spermidine, using S-adenosylmethione as substrate. Ornithine can be used by ornithine decarboxylase (OCD) to produce proline or by ornithine aminotransferase (OAT) to produce glutamine. (B) The absence of parasite arginase in $\mathrm{La}$-arg- ${ }^{-}$-infected macrophages increased arginine availability, production of higher levels of citrulline, and allowed a slight increase in ornithine production, altering the levels of polyamines and trypanothione disulfide. Red color indicates increased levels of metabolites, and green indicates reduced levels of metabolites. nd - not determined (C) Using an untargeted CE-MS, the intensity peak area of metabolites from the metabolic profile of macrophages infected with $L a$-WT or La-arg- and uninfected were compared, focusing on the L-arginine metabolism pathways. The graphs are representing the average metabolite amount in each group. $\left.{ }^{* *}\right) p$-value $<0.01 ;\left({ }^{* *}\right) p$-value $<0.005 ;\left({ }^{* * *}\right) p$-value $<0.001$, was used non-parametric 1-way ANOVA test (Kruskal-Wallis). 

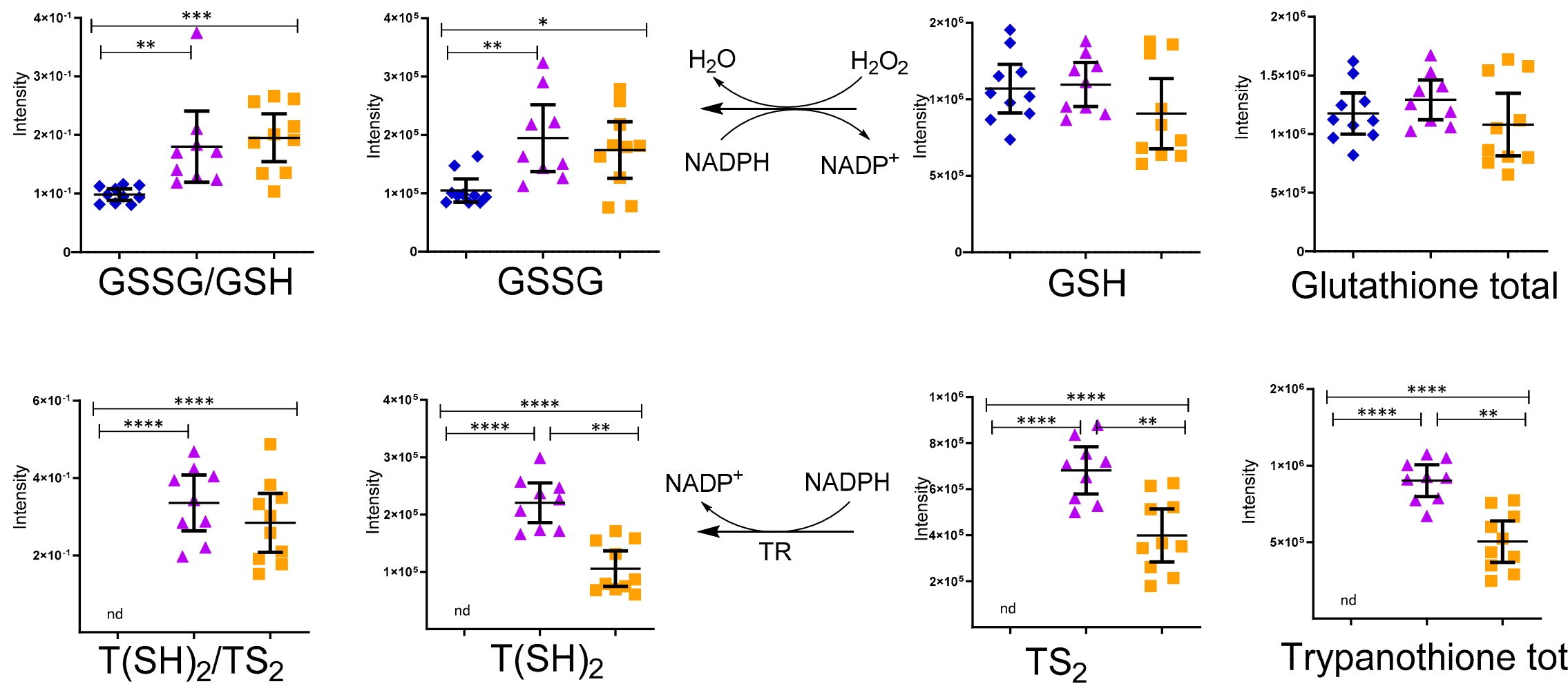

$\mathrm{TS}_{2}$

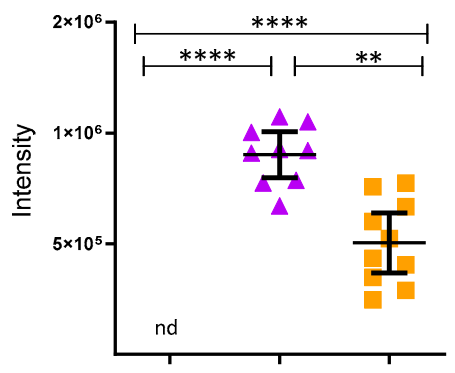

Trypanothione total

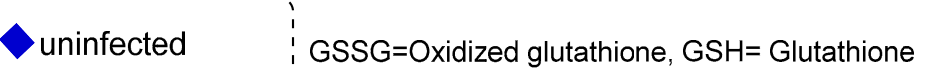

$\triangle$ C57BL/6-La-WT $: \mathrm{T}(\mathrm{SH})_{2}=$ Trypanothione disulfide, $\mathrm{TS}_{2}=$ Trypanothione

C57BL/6-La-arg-

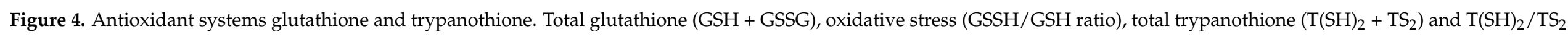

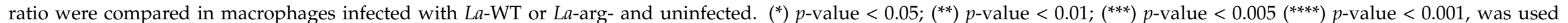
non-parametric 1-way ANOVA test (Kruskal-Wallis). 


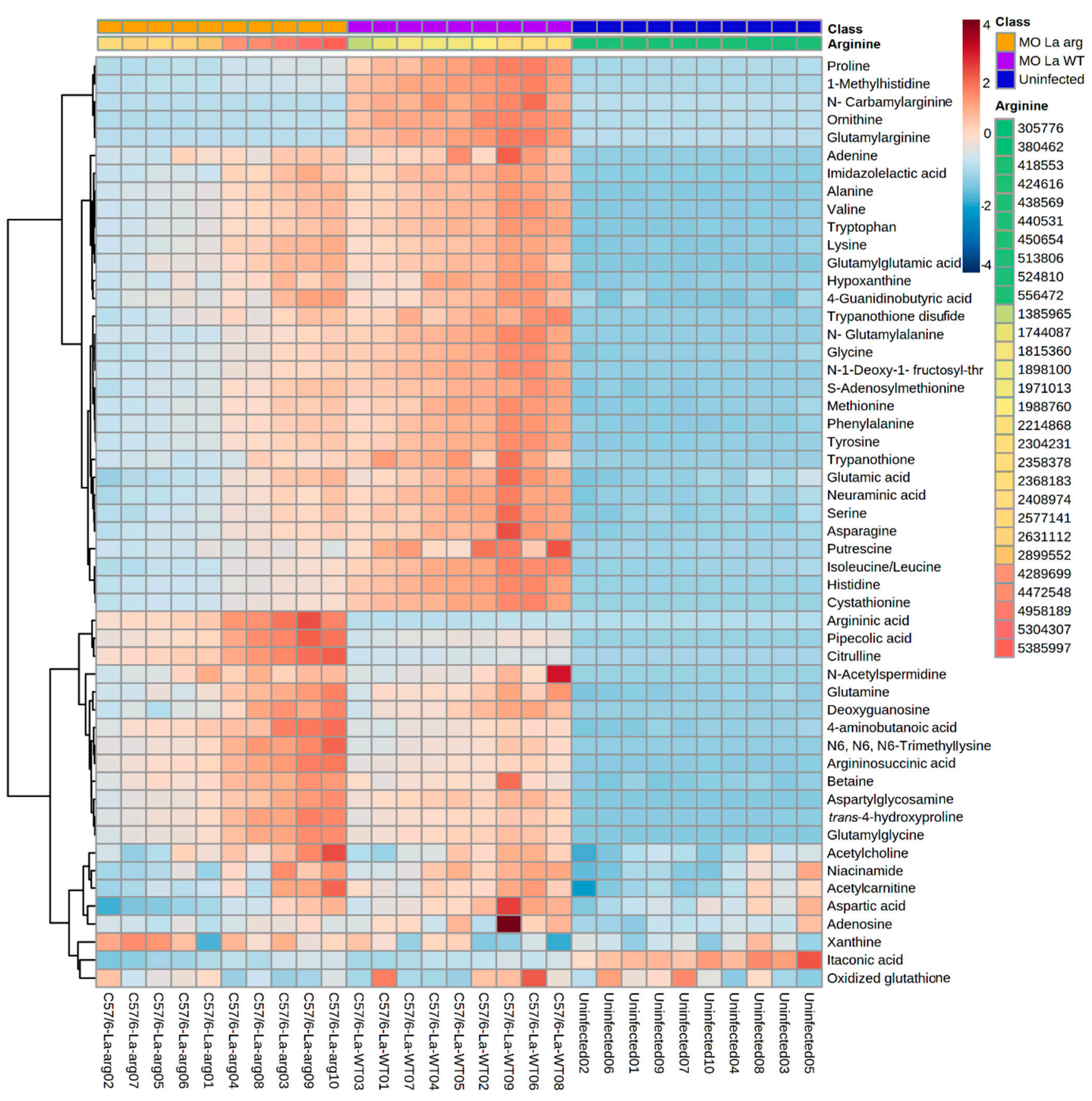

Figure 5. Heatmap of 53 metabolites differentially modulated in the metabolomic analysis of macrophages infected with $L a-W T$ or $L a-$ arg $^{-}$versus uninfected macrophages. Each column represents a sample, and each row represents a metabolite. Two factors order the samples: the first is arranged in three main groups (Phenotype: uninfected, $L a$-arg ${ }^{-}$and $L a-W T$ ), and inside each one, samples are ordered by the abundance of arginine, that has a pseudo-color ranging from the lowest amount-green; to the highest-red. The color code inside the heatmap depicts each metabolite relative fold change between groups. The parameters used for the analysis were the Euclidean distance measure and the Ward cluster algorithm.

\section{Discussion}

Macrophage activation and functional plasticity are strictly connected to metabolic reprogramming, supplying energy and metabolite participation in anabolic and catabolic pathways, modifying cell response to infections. Macrophages alter the demands for 
glucose, fatty acids, amino acids, purines, ATP, and NADPH to allow an appropriate response against pathogens, avoiding excessive inflammation or tissue injury [42,43].

Additionally, Leishmania can regulate its metabolites content during the differentiation from promastigote to amastigote inside macrophages. They can also evade microbicidal mechanisms $[44,45]$. Leishmania is auxotrophic for many nutrients that the amastigote can uptake from phagolysosomes, such as amino acids, lipids, purines, pyrimidines, heme, and vitamins $[34,46,47]$. The metabolite uptake and de novo synthesis correlate with virulence maintenance and parasite survival and can be favored by phagolysosome niche $[34,46,47]$. Many studies have shown that the metabolism from parasites interfere in macrophage metabolisms, but this is still poorly understood. However, to fill this gap, our group has previously demonstrated the influence of L. amazonensis arginase in the metabolism of promastigotes forms, changing the arginine, glutamine, and proline profile, as well as interfering in polyamines biosynthesis, as revealed by CE-ESI(+)-MS strategy [33]. Additionally, the changes in arginine levels and metabolism were shown in L. braziliensis resistant to antimony treatment, through CE-ESI(+)-MS strategy [33], evidencing alterations in the amino acids content and metabolism, and thiol-dependent redox [48].

Clinical data of diffused cutaneous leishmaniasis (DCL) showed that patients present higher ornithine, spermidine, and citrulline in plasma samples than mucocutaneous leishmaniasis (MCL), using HPLC tool [49]. Indeed, DCL skin biopsies upregulated arginase 1 (ARG1) and spermine synthase mRNAs involved in polyamines biosynthesis concerning localized cutaneous leishmaniasis (LC) and MCL lesions, highlighting the significance of host ARG1 and arginine transporter (cationic amino acid transporter, CAT2) in MCL [49]. However, the ARG1 and arginase 2 (ARG2) transcripts are lower in DCL than healthy controls [49]. L. amazonensis infection of BALB/c-macrophages increases host Cat2 and Arg1 transcripts, parasite arginine transporter (amino acid permease 3, AAP3), and parasite arginase [23]. Despite this, C57BL/6-macrophages infected with L. amazonensis did not modulate those genes $[28,50]$.

Additionally, the evaluation of metabolome fingerprint of early infection of L. amazonensis BALB/c infected macrophages by CE-ESI(+)M showed a modified blend of metabolite content, changing the amino acids, polyamines, and purine pathways [24]. Similar to the observed BALB/c macrophages infected with L. amazonensis [24], C57BL/6-macrophages also showed increased L-arginine levels, ornithine, and putrescine, supporting the metabolization of L-arginine in polyamines, which supply the production of trypanothione in detriment of glutathione.

However, L-arginine is used to produce polyamines, and is necessary to access the main M1 character: NO production. This production is dependent on the availability of the amino acid, $\mathrm{O}_{2}$ plus the co-factors: reduced nicotinamide-adenine-dinucleotide phosphate (NADPH), flavin adenine dinucleotide (FAD, flavin mononucleotide (FMN), and tetrahydrobiopterin $\left(\mathrm{BH}_{4}\right)$. Unlike the constitutive forms, NOS2 depends on calmodulin and heme to form a functional homodimer [11,12,51]. Contrasting with L. amazonensis infection of BALB/c macrophages that presents lower levels of NOS2, NO, and citrulline [22-24], the increased levels of citrulline in C57BL/6-macrophages infected with L. amazonensis compared to uninfected ones support the high levels of NO production by NOS2 and the reduction in infected macrophages in the time-course of infection. Additionally, a low levels of amastigotes inside C57BL/6-macrophages, as observed in the time-course of in vitro infection (Supplementary Figure S1) can be seem, in contrast to observed in susceptible BALB/c macrophage [24]. The absence of parasite arginase had no effect on the number of amastigotes per macrophages at $4-48 \mathrm{~h}$, suggesting parasite were not multiplying. The higher levels of frequency of NO producing cells increased the MFI of DAF-FM labeling per cell, and citrulline in C57BL/ 6 macrophages infected with $\mathrm{La}$-argindicate a microbicidal macrophages phenotype in this condition. It is interesting to note that the correlation of ARG1/NOS2 ratio and increase in susceptibility to Leishmania infection is extensively studied [52], but more information can be explored in the relation of polyamines/NO production. However, polyamines production can reduce NO production, 
as they are cross-inhibiting pathways. Polyamines are polycationic metabolites crucial for cell proliferation, gene transcription, protein translation, oxidative stress regulation, and immunosuppression signals [44,53-55]. Their biosynthesis also depend on arginine content competing with NO production $[29,56,57]$. The intricate cascade of enzymes that use L-arginine and their substrates or products and transporters allows the integration of polyamines biosynthesis with other metabolites, modulating the immune response [58,59]. Furthermore, increased ornithine levels, a product of ARG1, in C57BL/6 macrophages infected with $L$. amazonensis can be converted in proline, as indicated by its higher levels suggesting ornithine cyclodeaminase (OCD) activity (Figure 3A,C) [60,61]. Ornithine and proline can supply the increased levels of glutamate and glutamine in a complex enzyme network $[59,62]$ involving the production of metabolites: L-1-pyrroline 5-carboxylate, Lglutamate 5-semialdehyde, and L-glutamyl-P, [44] which are characterized in macrophages metabolism but are not identified by our method of analysis.

Further, we found the same spermidine levels between $L a-W T$ infected and uninfected macrophages, but higher S-adenosylmethionine and $\mathrm{N}$-acetylspermidine levels in infected macrophages (Figure 3A,C). S-adenosylmethionine donates an aminopropyl group to spermidine and spermine guided by aminopropyl transferases called spermidine synthase and spermine synthase $[59,62]$. The S-acetylspermidine is a polyamine with an acetyl group at the spermidine $N_{1}$-position received by spermidine/spermine $N_{1}$-acetyltransferase (SSAT) [63]. The mammalian cell polyamine content is maintained by enzymes that have a crucial role to this [64-66], we can exemplify: a) ARG1; b) OODC; c) SSAT; d) APAO (acetyl polyamine oxidase-which converts $N_{1}$-acetylspermidine into putrescine plus $\mathrm{N}$-acetyl-3aminopropanaldehyde [67]; and e) SMO (spermine oxidase-which converts spermine to spermidine plus 3-aminopropanaldehyde) [68,69]. Although found in mammalian cells, an $\mathrm{APO}$ and SMO [70] in Leishmania must be confirmed.

Another role of polyamines in the control of translation, mediated by spermidine, is an essential activity in the activation of eukaryotic initiation factor 5A (eIF5A), adding a hypusine through a process that cleaves the spermidine and transfer of 4-aminobutyl moiety to an internal lysine to form an intermediate deoxyhypusine and subsequently hypusine residue and mature eIF5A, being a post-translational modification. This protein modification is required to synthesize proteins in host cells [55,71,72] and Leishmania [73].

Regarding the redox state control, L-arginine serves as a glutathione source, which has particular relevance when detoxifying the cell from mitochondrial oxidants, regulating the redox environment [62]. The relative increase in oxidized glutathione (glutathione disulfide, GSSG)/reduced glutathione (glutathione, GSH) ratio observed in $L a$-WT and $L a$ $\mathrm{arg}^{-}$infected macrophages versus uninfected macrophages may indicate this response led to the oxidative stress condition (Figure 4). Peroxides oxidize GSH glutathione in a reaction catalyzed by glutathione peroxidase (GPx), ligating two reduced glutathione (GSH) with a disulfide bond, forming the GSSG. This reaction diminishes peroxide levels, removing these oxidants $[74,75]$. The turnover is mediated by the reduction in GSSG to GSH using NADPH as an electron donor. Glutathione reductase (GR) mediates this reaction. Additionally, glutathione biosynthesis is involved in resistance to anti-leishmanicidal agent pentavalent antimonial ( $\mathrm{Sb} \mathrm{V}$ ) [76]. The fine-tuning integration of oxidative stress and polyamines biosynthesis may balance the parasite killing in macrophages.

The integration of those pathways can be seen by analyzing the level of S-adenosylmethionine that is increased in the $\mathrm{La}$-arg- infected macrophages in relation to non-infected macrophages but decreased in relation to the La-WT infected macrophages, although the levels of glutathione were similar in any of these macrophages. The decrease in $\mathrm{S}$-adenosylmethionine in $\mathrm{La}$-arg ${ }^{-}$infected macrophages could be explained as a compensatory effect as it should be used to produce glutathione as well as to supply the production of putrescine, spermine, and spermidine as these molecules can be taken by the parasite to produce trypanothione, as parasite ornithine-putrescine-spermine-spermidine pathway is harmed by the absence of arginase activity. However, this possible compensation is not 
enough to reach the same levels of trypanothione in the $\mathrm{La}^{-\mathrm{arg}^{-}}{ }^{-}$infected macrophages compared to the detected in WT infected macrophages.

In fact, trypanosomatids do not show glutathione, but an analogous: trypanothione, formed by conjugation of spermidine and glutathione by trypanothione synthetase amidase (TRYS), unique in T. brucei, T. cruzi, and Leishmania spp. [77-82], and presenting a crucial function in combat oxidative stress $[83,84]$ and resistance to anti-trypanosome drugs $[79,85,86]$. This molecule is also related to L-arginine metabolism. We also found higher oxidized trypanothione (trypanothione disulphide, $\mathrm{T}\left(\mathrm{SH}_{2}\right)$ ) / reduced trypanothione (trypanothione, $\mathrm{TS}_{2}$ ) ratio in macrophages infected with $\mathrm{La}$-WT compared to $L a$-arg ${ }^{-}$or uninfected macrophages, probably impacting on the redox state (Figure 4). We suggest that this can also influence in the macrophage killing activity $[62,87,88]$. Similarly to glutathione, trypanothione needs to be recycled, depending on the NADPH availability produced by the pentose phosphate pathway (PPP) and the balance of competition between NADPH electron donors for NOS2 to produce NO, and NADPH oxidase to produce ROS and trypanothione reductase [87-90]. Notably, the higher levels of NO in La-arg-infected compared to La-WT-infected macrophages appeared in accord with higher levels of xanthine, once $\mathrm{NO}$ can help to inactive xanthine dehydrogenase and xanthine oxidase (interconvertible forms of xanthine oxidoreductase), increasing xanthine and decreasing ROS production and assisting in balancing damaging and helpful outcomes [91,92]. Another antioxidant molecule involved in protecting both host and parasite against oxidative stress is pipecolate, related to proline-ornithine metabolism, found in higher levels in $\mathrm{La}^{-\mathrm{arg}^{-}}{ }^{-}$-infected compared to La-WT-infected macrophages (Table 1 and Figure 6) [82].

In accordance, the arginase absence influences glutamate and proline metabolism. It increases polyamines production and arginine, citrulline, and argininic acid levels. It also decreases putrescine, proline, ornithine, glutamic acid, S-adenosylmethionine, cystathionine, and $\mathrm{N}$-carbamylarginine levels (Table 1 and Figure 6). Despite that, in a previous study, we did not find a modulation of the transcript levels involved in these metabolic pathways in the L. amazonensis infection context, comparing macrophages infected with La-WT and $L a-\arg ^{-}[50]$. 


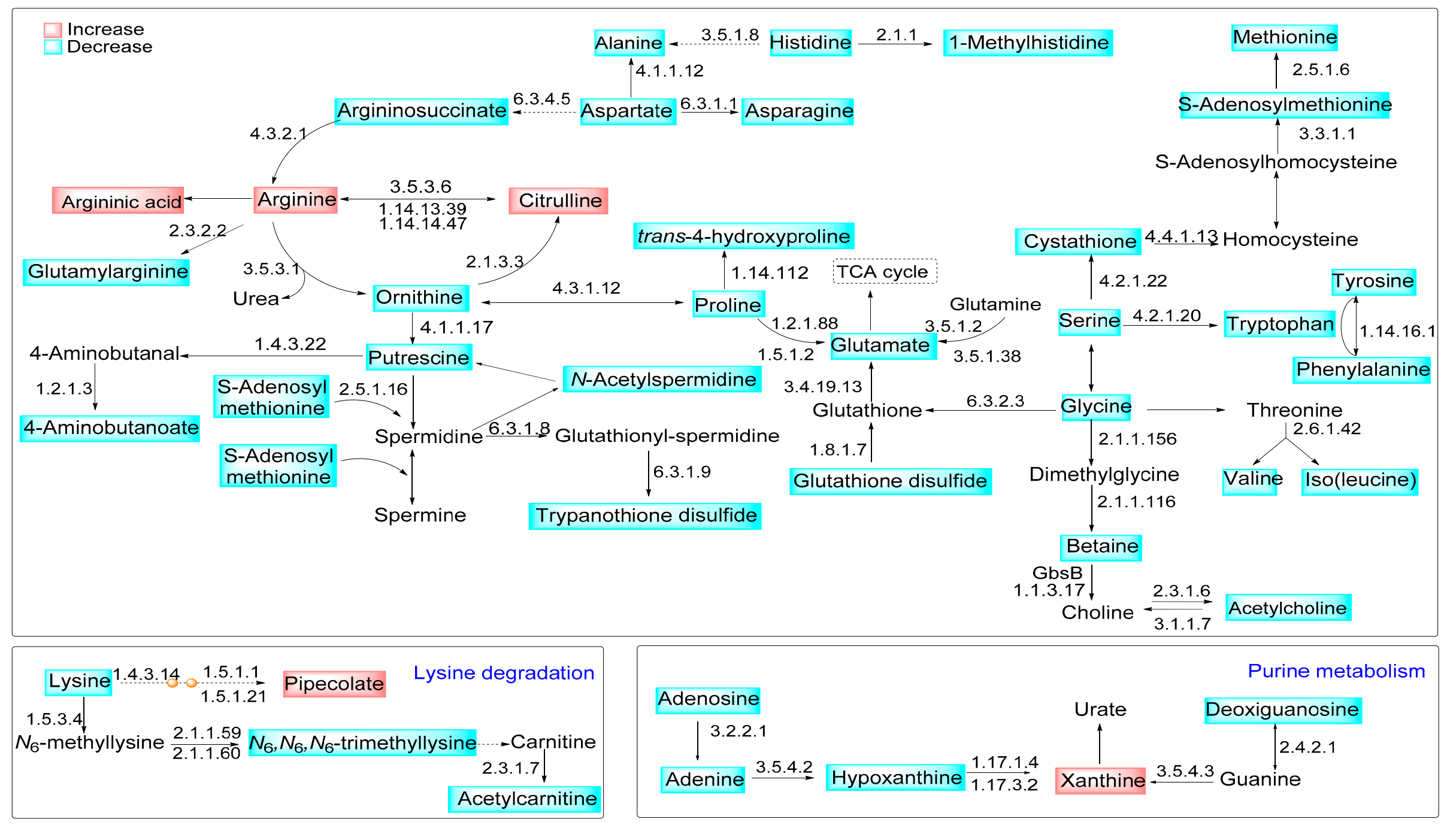

Figure 6. Modulation of metabolite content in the L-arginine metabolic pathways in macrophages infected with $L a-$ arg $^{-}$compared to La-WT. Representation of modulated metabolic pathways during the infection of macrophages with L. amazonensis. The blue boxes represent the decreased metabolites, while the red boxes represent the increased metabolites in the comparison of $L a-a^{-}{ }^{-}$to $L a-W T$. The KEGG EC entry of enzymes involved in the pathway is shown as a number close to the arrows, indicating the catalyzed reactions. 


\section{Materials and Methods}

\subsection{In Vitro Macrophage Infections}

The Bone Marrow Derived Macrophages (BMDM) were seeded into 24-well plates (SPL Lifescience, Pocheon, Korea) $\left(5 \times 10^{5} / \mathrm{SPL}\right)$ for infectivity and NO production analysis, or into 6-well plates (SSPL Lifescience, Pocheon, Korea) $\left(5 \times 10^{6} /\right.$ well) for metabolite analysis. After $18 \mathrm{~h}$ of incubation at $34{ }^{\circ} \mathrm{C}$ in an atmosphere of $5 \% \mathrm{CO}_{2}, \mathrm{BMDMs}$ were infected with $L a-W T$ or $L a-a^{-}{ }^{-}$promastigotes in the stationary growth phase (MOI 5:1). After $4 \mathrm{~h}$ of infection, non-phagocyte promastigotes were washed with fresh medium, and samples were collected for metabolite extraction or fixed for infectivity index determination. The uninfected macrophages were maintained in the same conditions. (See Supplementary Information for details of macrophage harvest).

\subsection{Infectivity Quantification}

For infectivity analysis, before infection $\mathrm{La}$-WT or La-arg- promastigotes were labeled with $5 \mu \mathrm{M}$ Carboxyfluorescein succinimidyl ester (CFSE) (Invitrogen) for $30 \mathrm{~min}$ and washed in RPMI supplemented as previously described (see Supporting Information for details of parasite culture). The infectivity was analyzed by Image Flow Cytometry (Amnis - Amnis Corporation, Seattle, WA, USA) after cell-fixation with $1 \%$ paraformaldehyde (Merck, Darmstadt, Germany) for $20 \mathrm{~min}$ at $4{ }^{\circ} \mathrm{C}$, followed by PBS washing. Infectivity was analyzed in Spot Count wizard (ideas Software, Amnis), single gating cells, and $\mathrm{CFSE}^{+}$population (infected macrophages) to count the number of amastigotes per infected/macrophage in at least 80,000 macrophages in three independent experiments. The infection index was calculated by multiplying the macrophage infection rate by the mean number of amastigotes per macrophage.

\subsection{NO Quantification}

For NO quantification, after $4 \mathrm{~h}$ of infection, macrophages were ungripped by incubation with $1 \mathrm{mM}$ EDTA in PBS $1 \mathrm{X}$ for $10 \mathrm{~min}$ at $34^{\circ} \mathrm{C}$ and cell scraping on ice after adding RPMI plus $10 \%$ FBS. Cells were centrifuged $\left(500 \times g, 10 \mathrm{~min}, 4^{\circ} \mathrm{C}\right)$ and FBS was resuspended in $50 \mu \mathrm{L}$ of $5 \mu \mathrm{M}$ of Diaminofluorescein-FM Diacetate (DAF-FM). After $30 \mathrm{~min}$ of incubation, cells were washed and resuspended in cold PBS 1X. NO was quantified by image flow cytometry, gating the frequency of DAF-FM+ ${ }^{+}$cell and the media MFI of DAF-FM.

\subsection{CE-MS Metabolic Fingerprinting}

Sample preparation was performed following a protocol previously described (see Supplementary Information for details of Metabolite Extraction) [33]. The extracts obtained were analyzed by capillary electrophoresis system (7100 Agilent Technologies, Santa Clara, CA, USA) coupled to a time-of-flight mass spectrometer (6224 Agilent Technologies), the coupling was equipped with an ESI sprayer G1607 from Agilent Technologies. The compounds were separated in a fused silica capillary (Agilent Technologies) with a total length of $100 \mathrm{~cm}$ and an internal diameter of $50 \mu \mathrm{m}$ in normal polarity with a background electrolyte (BGE) containing $1.0 \mathrm{M}$ formic acid solution in $10 \%$ methanol $(v / v)$. New capillaries were pre-conditioned with a flush $(950 \mathrm{mbars})$ of $\mathrm{NaOH} 1.0 \mathrm{M}$ for $30 \mathrm{~min}$, followed by MilliQ water for $30 \mathrm{~min}$ and BGE for $30 \mathrm{~min}$. Before each analysis, the capillaries were conditioned with BGE for $5 \mathrm{~min}$. Samples were hydro-dynamically injected at $50 \mathrm{mbar}$ for $50 \mathrm{~s}$, and stacking was carried out, applying BGE at $100 \mathrm{mbar}$ for $10 \mathrm{~s}$. Metabolite separation occurred when a voltage of $30 \mathrm{kV}$ with 25 mbar of internal pressure was applied. The observed current during the experiment under these conditions was $23 \mu \mathrm{A}$.

The sheath liquid flow composition was methanol/water 50:50 $(v / v)$ with two reference standards, purine $\left(\mathrm{C}_{5} \mathrm{H}_{4} \mathrm{~N}_{4}, m / z\right.$ 121.0509) and HP-0921 $\left(\mathrm{C}_{18} \mathrm{H}_{18} \mathrm{O}_{6} \mathrm{~N}_{3} \mathrm{P}_{3} \mathrm{~F}_{24}, m / z\right.$ 922.0098), for mass accuracy monitoring was supplied by ISO Pump 1200 from Agilent Technologies Santa Clara, CA, USA. After the separated sample compounds leave the 
capillary, a positively charged spray is formed by a flow of the sheath liquid $\left(6 \mu \mathrm{L} \mathrm{min}{ }^{-1}\right)$, a nitrogen spraying pressure of $10 \mathrm{psi}$, and a capillary voltage of $3500 \mathrm{~V}$. The spray is dried

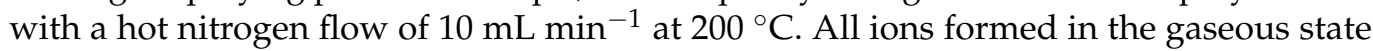
are directed to the TOF-MS following the parameter voltages: fragmentor $125 \mathrm{~V}$, skimmer $65 \mathrm{~V}$, and octopole $750 \mathrm{~V}$. Data were collected in the positive ionization $(+)$ mode of ESI, and ions between 70 and 1000 Da were acquired at a scan rate of 1.41 scans per second. All systems were controlled by Agilent MassHunter TOF data acquisition software version B.06.01 (Agilent Technologies Inc.).

\subsection{CE-MS Data Treatment}

Data acquired after CE-MS analysis were processed using MassHunter Profinder (B.10.00, Agilent Technologies Santa Clara, CA, USA) to obtain a data matrix. The software first performed an alignment and correlation of all electropherograms migration time using a specific algorithm for $\mathrm{CE}$. Then, the software applies two consecutive algorithms to perform the deconvolution. First, it performs the extraction of the critical variables (compounds) and reduces the data by removing the unspecified information. A second algorithm improves the reliability of the search for data features. The Find by Ion (FbI) algorithm performs a targeted extraction of specific features. The abundance of the molecule, mass accuracy, and migration time of each feature in all samples was finally obtained as matrix data. Data quality was ensured by excluding background noise and non-related ions, the characteristics present in the QC were maintained at 50\%. For missing values, the k-nearest neighbors ( $\mathrm{kNN}$ ) algorithm was applied. Data was re-filtered on relative standard deviation (RSD in the QC features were removed from all samples with an RSD 30\%).

\subsection{Statistical Analysis}

We used the non-normalized data for multivariate analysis (MVA) and univariate statistics (UVA). A center scaling was used for MVA using SIMCA 16.0.1 software (Umea, Sweden). Unsupervised principal component analysis (PCA) was used to verify the quality of analysis, detect outliers, and check sample patterns. A partial least squares discriminant analysis (PLS-DA) model and orthogonal OPLS-DA were carried out to discriminate variation between groups. Model aptitude and predictive ability were evaluated using the explained variance $\left(R^{2}\right)$ and predicted variance $\left(Q^{2}\right)$, respectively, provided by the software. For UVA, we used MATLAB R2015a software (Mathworks, Inc., Natick, MA, USA), and a non-parametric 1-way ANOVA test (Kruskal-Wallis) was used to obtain the significant signals, followed by the Benjamini-Hochberg post hoc correction (FDR false discovery rate) $(q=0.05)$. Additionally, pairwise comparisons were obtained using the Mann-Whitney U-test. The level of statistical significance was established with a $95 \%$ confidence interval $(p<0.05)$. Finally, the percentage change was calculated $(\%)$. For infectivity and NO production analysis, the differences were evaluated by Student $t$-test (GraphPad software version 7).

\subsection{Pathway Enrichment Analysis}

Aiming to understand which pathways were modulated during the macrophage infection with L. amazonensis and evaluate how the parasite arginase can impact them even more. The biological pathways involved in the metabolism of the 53 metabolites from $\mathrm{La}$ WT and $\mathrm{La}$-arg ${ }^{-}$infected C57BL/6-macrophages differentially modulated in comparison with uninfected and the biological function were analyzed by enrichment analysis using MetaboAnalyst (Figure S5). The corresponding pathways were shown based on $p$ values from the enrichment analysis ( $y$-axis) and fold enrichment ( $x$-axis). The top 10 most impacted pathways were colored in red, and measured as closely related to Leishmaniainfection of C57BL/6-macrophage, including urea cycle, glycine, and serine metabolism, ammonia recycling, methionine metabolism, aspartate metabolism, glutamate metabolism, spermidine and spermine biosynthesis, methylhistidine metabolism, and glutathione metabolism, supporting the involvement of arginine metabolism during infection. As 
expected, we observed that the amino acid L-arginine pathways were the most impacted during the infection.

This information guides us to integrate the differential regulated metabolites from arginine metabolism with other pathways in $L a$-WT infected macrophages versus $L a$-arg ${ }^{-}$ infected macrophages, as shown in Figure 6. The higher levels of arginine correlate with increased production of citrulline and ornithine. Ornithine support increased levels of trypanothione via polyamines production. Putrescine and spermidine were converted into glutathionylspermidine, and subsequent in trypanothione disulfide increased in $\mathrm{La}$ WT infected macrophages. Additionally, ornithine can be interconverted in proline, and glutamate, raising the glutathione disulfide, both in higher infected macrophages. The alteration in pipecolate and xanthine levels showed the influences of Leishmania infection in the lysine degradation and purine metabolism.

\subsection{Ethics Statement}

The experimental protocol was approved by the Comissão de Ética no Uso de Animais (CEUA-approval number CEUA-IB: 314/2018)) from the Institute of Bioscience of the University of São Paulo. This study was carried out according to the recommendations in the guide and policies for the care and use of laboratory animals of the Brazilian government (Lei Federal 11.794, de 08/10/2008).

\section{Conclusions}

In conclusion, the parasite arginase plays a role in the metabolism of C57BL/6 macrophages infected with Leishmania, involving the metabolism of arginine, proline, and glutamate, and polyamines biosynthesis. It can be implicated in redox balance of host and parasite cells by oxidization and reduction in glutathione and trypanothione, NO production, influencing in the microbicidal activity of macrophages and parasite survival. The extrapolation of in vitro infections data to in vivo models or natural infection by Leishmania is not simple, but our data can contribute to the understanding of the early infection changes in the metabolic profile leading to macrophages response to infection [45].

Supplementary Materials: The following are available online at https://www.mdpi.com/article/10 $.3390 /$ ijms22136883/s1.

Author Contributions: M.M.-H., S.M.M., S.M.A., L.M.F.-W., and Á.L.-G. conceived and designed the experiments. M.M.-H., S.M.M., S.M.A., and Á.L.-G. performed the experiments and analyzed the data. M.M.-H., S.M.M., S.M.A., L.M.F.-W., C.B., and Á.L.-G. wrote and revised the paper. All authors have read and agreed to the published version of the manuscript.

Funding: This work was supported by grants from the Conselho Nacional de Desenvolvimento Científico e Tecnológico (CNPq, http: / / www.cnpq.br: 406351/2018-0) and Fundação de Amparo à Pesquisa do Estado de São Paulo [FAPESP, http:/ / www.fapesp.br (accessed May 2021): 2018/235120; 2018/24693-9] and Innovation and Universities of Spain (MICINN) and FEDER funding [Ref. RTI2018-095166-B-I00]). M.M.-H. is supported by a fellowship from CEU-International Doctoral School (CEINDO). S.M.A. is supported by a fellowship from FAPESP (2017/23519-2).

Institutional Review Board Statement: The study was approved by Comissão de Ética no Uso de Animais (CEUA-approval number CEUA-IB: 314/2018)) from the Institute of Bioscience of the University of São Paulo and carried out according to the recommendations in the guide and policies for the care and use of laboratory animals of the Brazilian government (Lei Federal 11.794, de 08/10/2008).

Informed Consent Statement: Not applicable.

Data Availability Statement: Data is contained within the article or supplementary material.

Conflicts of Interest: The authors have declared no conflicts of interest. The funders had no role in the design of the study; in the collection, analyses, or interpretation of data; in the writing of the manuscript, or in the decision to publish the results. 


\section{Abbreviations}

NOS2 nitric oxide synthase 2, NO nitric oxide, CAT2 cationic amino acid transporters 2, ARG1 arginase 1, AAP3 amino acid permease 3, La-WT Leishmania amazonensis-wild type, La-arg- Leishmania amazonensis-arginase knockout, CE-MS Capillary Eletrophoresis-Mass Spectrometer, BMDMs bone marrow-derived macrophages.
\end{abstract}

\title{
References
}

1. Martinez, F.O.; Sica, A.; Mantovani, A.; Locati, M. Macrophage activation and polarization. Front. Biosci. 2008, 13, 453-461. [CrossRef]

2. Vogel, D.Y.S.; Glim, J.E.; Stavenuiter, A.W.D.; Breur, M.; Heijnen, P.; Amor, S.; Dijkstra, C.D.; Beelen, R.H.J. Human macrophage polarization in vitro: Maturation and activation methods compared. Immunobiology 2014, 219, 695-703. [CrossRef] [PubMed]

3. Filardy, A.A.; Pires, D.R.; Nunes, M.P.; Takiya, C.M.; Freire-de-Lima, C.G.; Ribeiro-Gomes, F.L.; DosReis, G.A. Proinflammatory clearance of apoptotic neutrophils induces an IL-12 low IL-10 high regulatory phenotype in macrophages. J. Immunol. 2010, 185, 2044-2050. [CrossRef]

4. Boucher, J.L.; Moali, C.; Tenu, J.P. Nitric oxide biosynthesis, nitric oxide synthase inhibitors and arginase competition for L-arginine utilization. Cell. Mol. Life Sci. 1999, 55, 1015-1028. [CrossRef] [PubMed]

5. Hrabak, A.; Bajor, T.; Temesi, A.; Meszaros, G. The inhibitory effect of nitrite, a stable product of nitric oxide (NO) formation, on arginase. FEBS Lett. 1996, 390, 203-206. [CrossRef]

6. Mantovani, A.; Sica, A.; Sozzani, S.; Allavena, P.; Vecchi, A.; Locati, M. The chemokine system in diverse forms of macrophage activation and polarization Trends Immunol. Trends Immunol. 2004, 25, 677-686. [CrossRef]

7. Van den Bossche, J.; Baardman, J.; de Winther, M.P.J. Metabolic characterization of polarized M1 and M2 bone marrow-derived macrophages using real-time extracellular flux analysis. J. Vis. Exp. 2015, 28, e53424. [CrossRef]

8. Covarrubias, A.J.; Aksoylar, H.I.; Horng, T. Control of macrophage metabolism and activation by mTOR and Akt signaling. Semin. Immunol. 2015, 27, 286-296. [CrossRef] [PubMed]

9. Vergadi, E.; Ieronymaki, E.; Lyroni, K.; Vaporidi, K.; Tsatsanis, C. Akt signaling pathway in macrophage activation and M1/M2 polarization. J. Immunol. 2017, 198, 1006-1014. [CrossRef] [PubMed]

10. Rafferty, S.; Malech, H.L. High reductase activity of recombinant NOS2 flavoprotein domain lacking the calmodulin binding regulatory sequence. Biochem. Biophys. Res. Commun. 1996, 220, 1002-1007. [CrossRef] [PubMed]

11. Jha, A.K.; Huang, S.C.C.; Sergushichev, A.; Lampropoulou, V.; Ivanova, Y.; Loginicheva, E.; Chmielewski, K.; Stewart, K.M.; Ashall, J.; Everts, B.; et al. Network integration of parallel metabolic and transcriptional data reveals metabolic modules that regulate macrophage polarization. Immunity 2015, 42, 419-430. [CrossRef] [PubMed]

12. Blagih, J.; Jones, R.G. Polarizing macrophages through reprogramming of glucose metabolism Cell. Metab. 2012, 15, 793-795. [CrossRef]

13. Koo, S.j.; Garg, N.J. Metabolic programming of macrophage functions and pathogens control. Redox Biol. 2019, $24,101198$. [CrossRef]

14. Tannahill, G.M.; Curtis, A.M.; Adamik, J.; Palsson-McDermott, E.M.; McGettrick, A.F.; Goel, G.; Frezza, C.; Bernard, N.J.; Kelly, B.; Foley, N.H.; et al. Succinate is an inflammatory signal that induces IL-1beta through HIF-1alpha. Nature 2013, 496, 238-242. [CrossRef] [PubMed]

15. O'Neill, L.A.; Kishton, R.J.; Rathmell, J. A guide to immunometabolism for immunologists. Nat. Rev. Immunol. 2016, 16, 553-565. [CrossRef] [PubMed]

16. Wang, N.; Liang, H.; Zen, K. Molecular mechanisms that influence the macrophage m1-m2 polarization balance. Front. Immunol. 2014, 15, 614. [CrossRef]

17. Whyte, C.S.; Ruckerl, D.; Bishop, E.; Barker, R.N.; Rees, A.; Allen, J.; Wilson, H.M. Regulation of alternative (M2) macrophage activation by Suppressor of Cytokine Signalling (SOCS) 1. Immunology 2010, 131, 86.

18. Moore, K.J.; Sheedy, F.J.; Fisher, E.A. Macrophages in atherosclerosis: A dynamic balance. Nat. Rev. Immunol. 2013, 13, 709-721. [CrossRef]

19. Mills, C.D. M1 and M2 macrophages: Oracles of health and disease. Crit. Rev. Immunol. 2012, 32, 463-488. [CrossRef]

20. Burza, S.; Croft, S.L.L.; Boelaert, M. Leishmaniasis. Lancet 2018, 392, 951-970. [CrossRef]

21. Murray, H.W.W.; Berman, J.D.D.; Davies, C.R.R.; Saravia, N.G.G. Advances in leishmaniasis. Lancet 2005, 366, $1561-1577$. [CrossRef]

22. Aoki, J.I.; Muxel, S.M.; Zampieri, R.A.; Müller, K.E.; Nerland, A.H.; Floeter-Winter, L.M. Differential immune response modulation in early Leishmania amazonensis infection of BALB/c and C57BL/6 macrophages based on transcriptome profiles. Sci. Rep. 2019, 9, 1-14. [CrossRef]

23. Muxel, S.M.; Laranjeira-Silva, M.F.; Zampieri, R.A.; Floeter-Winter, L.M. Leishmania (Leishmania) amazonensis induces macrophage miR-294 and miR-721 expression and modulates infection by targeting NOS2 and L-arginine metabolism. Sci. Rep. 2017, 7, 44141. [CrossRef] [PubMed] 
24. Muxel, S.M.; Mamani-Huanca, M.; Aoki, J.I.; Zampieri, R.A.; Floeter-Winter, L.M.; López-Gonzálvez, Á.; Barbas, C. Metabolomic profile of BALB/c macrophages infected with Leishmania amazonensis: Deciphering l-arginine metabolism. Int. J. Mol. Sci. 2019, 20, 6248. [CrossRef] [PubMed]

25. Velasquez, L.G.; Galuppo, M.K.E.; De Rezende, E.; Brandao, W.N.; Peron, J.P.; Uliana, S.R.; Duarte, M.I.; Stolf, B.S. Distinct courses of infection with Leishmania (L.) amazonensis are observed in BALB/c, BALB/c nude and C57BL/6 mice. Parasitology 2016, 143, 692-703. [CrossRef] [PubMed]

26. Ji, J.; Sun, J.; Soong, L. Impaired expression of inflammatory cytokines and chemokines at early stages of infection with Leishmania amazonensis. Infect. Immun. 2003, 71, 4278-4288. [CrossRef] [PubMed]

27. Boitz, J.M.; Gilroy, C.A.; Olenyik, T.D.; Paradis, D.; Perdeh, J.; Dearman, K.; Davis, M.J.; Yates, P.A.; Li, Y.; Riscoe, M.K.; et al. Arginase is essential for survival of Leishmania donovani promastigotes but not intracellular amastigotes. Infect. Immun. 2017, 85, e00554-16. [CrossRef]

28. Muxel, S.M.; Acuña, S.M.; Aoki, J.I.; Zampieri, R.A.; Floeter-Winter, L.M. Toll-like receptor and miRNA-let-7e expression alter the inflammatory response in leishmania amazonensis-infected macrophages Front. Immunol. 2018, 9, 2792. [CrossRef]

29. Rath, M.; Müller, I.; Kropf, P.; Closs, E.I.; Munder, M. Metabolism via arginase or nitric oxide synthase: Two competing arginine pathways in macrophages. Front. Immunol. 2014, 5, 664. [CrossRef] [PubMed]

30. Roberts, S.C.; Tancer, M.J.; Polinsky, M.R.; Gibson, K.M.; Heby, O.; Ullman, B. Arginase plays a pivotal role in polyamine precursor metabolism in Leishmania. Characterization of gene deletion mutants. J. Biol. Chem. 2004, 279, 23668-23678. [CrossRef]

31. Da Silva, M.F.L.; Zampieri, R.A.; Muxel, S.M.; Beverley, S.M.; Floeter-Winter, L.M. Leishmania amazonensis arginase compartmentalization in the glycosome is important for parasite infectivity. PLoS ONE 2012, 7, e34022. [CrossRef] [PubMed]

32. Aoki, J.I.; Muxel, S.M.; Zampieri, R.A.; Laranjeira-Silva, M.F.; Müller, K.E.; Nerland, A.H.; Floeter-Winter, L.M. RNA-seq transcriptional profiling of Leishmania amazonensis reveals an arginase-dependent gene expression regulation. PLoS Negl. Trop. Dis. 2017, 11, e0006026. [CrossRef] [PubMed]

33. Castilho-Martins, E.A.; Canuto, G.A.B.; Muxel, S.M.; daSilva, M.F.L.; Floeter-Winter, L.M.; del Aguila, C.; López-Gonzálvez, Á.; Barbas, C. Capillary electrophoresis reveals polyamine metabolism modulation in Leishmania (Leishmania) amazonensis wild-type and arginase-knockout mutants under arginine starvation. Electrophoresis 2015, 13, 2314-2323. [CrossRef] [PubMed]

34. McConville, M.J. Metabolic crosstalk between Leishmania and the macrophage host. Trends Parasitol. 2016, 32, 666-668. [CrossRef] [PubMed]

35. McConville, M.J.; de Souza, D.; Saunders, E.; Likic, V.A.; Naderer, T. Living in a phagolysosome; metabolism of Leishmania amastigotes. Trends Parasitol. 2007, 23, 368-375. [CrossRef] [PubMed]

36. Aoki, J.I.; Muxel, S.M.; Zampieri, R.A.; Acuña, S.M.; Fernandes, J.C.R.; Vanderlinde, R.H.; Sales, M.C.O.D.P.; Floeter-Winter, L.M. L-arginine availability and arginase activity: Characterization of amino acid permease 3 in Leishmania amazonensis. PLoS Negl. Trop. Dis. 2017, 11, e0006025. [CrossRef] [PubMed]

37. Thompson, R.W.; Pesce, J.T.; Ramalingam, T.; Wilson, M.S.; White, S.; Cheever, A.W.; Ricklefs, S.M.; Porcella, S.F.; Li, L.; Ellies, L.G.; et al. Cationic amino acid transporter-2 regulates immunity by modulating arginase activity. PLoS Pathog. 2008, 4, e1000023. [CrossRef]

38. Wanasen, N.; Soong, L. L-arginine metabolism and its impact on host immunity against Leishmania infection. Immunol. Res. 2008, 41, 15-25. [CrossRef]

39. Laranjeira-Silva, M.F.; Zampieri, R.A.; Muxel, S.M.; Floeter-Winter, L.M.; Markus, R.P. Melatonin attenuates Leishmania (L.) amazonensis infection by modulating arginine metabolism. J. Pineal Res. 2015, 59, 478-487. [CrossRef] [PubMed]

40. Iniesta, V.; Gomez-Nieto, L.C.; Corraliza, I. The inhibition of arginase by N(omega)-hydroxy-l-arginine controls the growth of Leishmania inside macrophages. J. Exp. Med. 2001, 193, 777-784. [CrossRef] [PubMed]

41. Mamani-Huanca, M.; de la Fuente, A.G.; Otero, A.; Gradillas, A.; Godzien, J.; Barbas, C.; López-Gonzálvez, Á. Enhancing confidence of metabolite annotation in capillary electrophoresis-mass spectrometry untargeted metabolomics with relative migration time and in-source fragmentation. J. Chromatogr. A 2021, 1635, 461758. [CrossRef]

42. Locati, M.; Curtale, G.; Mantovani, A. Diversity, mechanisms, and significance of macrophage plasticity. Annu. Rev. Pathol. Mech Dis. 2020, 10, e0115855. [CrossRef] [PubMed]

43. Ryan, D.G.; O'Neill, L.A.J. Krebs cycle reborn in macrophage immunometabolism. Annu. Rev. Immunol. 2020, 38, 289-313. [CrossRef] [PubMed]

44. Muxel, S.M.; Aoki, J.I.; Fernandes, J.C.R.; Laranjeira-Silva, M.F.; Zampieri, R.A.; Acuña, S.M.; Müller, K.E.; Vanderlinde, R.H.; Floeter-Winter, L.M. Arginine and polyamines fate in leishmania infection. Front. Microbiol. 2018, 8, 2214. [CrossRef]

45. Rosenzweig, D.; Smith, D.; Opperdoes, F.; Stern, S.; Olafson, R.W.; Zilberstein, D. Retooling Leishmania metabolism: From sand fly gut to human macrophage. FASEB J. 2008, 22, 590-602. [CrossRef] [PubMed]

46. McConville, M.J.; Saunders, E.C.; Kloehn, J.; Dagley, M.J. Leishmania carbon metabolism in the macrophage phagolysosome-feast or famine? F1000Research 2015, 4, 938. [CrossRef] [PubMed]

47. Saunders, E.C.; Naderer, T.; Chambers, J.; Landfear, S.M.; McConville, M.J. Leishmania mexicana can utilize amino acids as major carbon sources in macrophages but not in animal models. Mol. Microbiol. 2018, 108, 143-158. [CrossRef] [PubMed]

48. Canuto, G.A.B.A.; Castilho-Martins, E.A.A.; Tavares, M.; Lopez-Gonzalvez, A.; Rivas, L.; Barbas, C.; López-Gonzálvez, Á.; Rivas, L.; Barbas, C. CE-ESI-MS metabolic fingerprinting of Leishmania resistance to antimony treatment. Electrophoresis 2012, 33, 1901-1910. [CrossRef] [PubMed] 
49. Malta-Santos, H.; França-Costa, J.; Macedo, A.; Queiroz, A.T.L.; Fukutani, K.F.; Muxel, S.M.; Khouri, R.; van Weyenbergh, J.; Boaventura, V.; Barral, A.; et al. Differential expression of polyamine biosynthetic pathways in skin lesions and in plasma reveals distinct profiles in diffuse cutaneous leishmaniasis. Sci. Rep. 2020, 10, 10543. [CrossRef] [PubMed]

50. Aoki, J.I.; Muxel, S.M.; Laranjeira-Silva, M.F.; Zampieri, R.A.; Müller, K.E.; Nerland, A.H.; Floeter-Winter, L.M. Dual transcriptome analysis reveals differential gene expression modulation influenced by Leishmania arginase and host genetic background. Microb. Genomics. 2020, 6, mgen000427. [CrossRef] [PubMed]

51. Zheng, X.; Fernando, V.; Sharma, V.; Walia, Y.; Letson, J.; Furuta, S. Correction of arginine metabolism with sepiapterin-the precursor of nitric oxide synthase cofactor BH4-Induces immunostimulatory-shift of breast cancer. Biochem. Pharmacol. 2020, 176, 113887. [CrossRef] [PubMed]

52. Bogdan, C. Macrophages as host, effector and immunoregulatory cells in leishmaniasis: Impact of tissue micro-environment and metabolism. Cytokine X 2020, 12, 100041. [CrossRef] [PubMed]

53. Pegg, A.E.; McCann, P.P. Polyamine metabolism and function. Am. J. Physiol. Cell. Physiol. 1982, 243, C212-C221. [CrossRef] [PubMed]

54. Thomas, T.; Thomas, T.J. Polyamines in cell growth and cell death: Molecular mechanisms and therapeutic applications. Cell. Mol. Life Sci. 2001, 58, 244-258. [CrossRef]

55. Puleston, D.J.; Buck, M.D.; Geltink, R.I.K.; Kyle, R.L.; Caputa, G.; O’Sullivan, D.; Cameron, A.M.; Castoldi, A.; Musa, Y.; Kabat, A.M.; et al. Polyamines and eIF5A hypusination modulate mitochondrial respiration and macrophage activation. Cell. Metab. 2019, 30, 352-363. [CrossRef] [PubMed]

56. Gogoi, M.; Datey, A.; Wilson, K.T.; Chakravortty, D. Dual role of arginine metabolism in establishing pathogenesis. Curr. Opin. Microbiol. 2016, 29, 43-48. [CrossRef] [PubMed]

57. Perez-Leal, O.; Barrero, C.A.; Clarkson, A.B.; Casero, R.A.; Merali, S. Polyamine-regulated translation of spermidine/spermineN1-scetyltransferase. Mol. Cell. Biol. 2012, 32, 1453-1467. [CrossRef] [PubMed]

58. Hesterberg, R.; Cleveland, J.; Epling-Burnette, P. Role of polyamines in immune cell functions. Med. Sci. 2018, 6, 22. [CrossRef] [PubMed]

59. Puleston, D.J.; Villa, M.; Pearce, E.L. Ancillary activity: Beyond core metabolism in immune cells. Cell. Metab. 2017, 26, 131-141 [CrossRef] [PubMed]

60. Wu, G.; Bazer, F.W.; Datta, S.; Johnson, G.A.; Li, P.; Satterfield, M.C.; Spencer, T.E. Proline metabolism in the conceptus: Implications for fetal growth and development. Amino Acids. 2008, 35, 691-702. [CrossRef]

61. Goodman, J.L.; Wang, S.; Alam, S.; Ruzicka, F.J.; Frey, P.A.; Wedekind, J.E. Ornithine cyclodeaminase: Structure, mechanism of action, and implications for the $\mu$-crystallin family. Biochemistry 2004, 43, 13883-13891. [CrossRef] [PubMed]

62. Dickinson, D.A.; Forman, H.J. Cellular glutathione and thiols metabolism. Biochem. Pharmacol. 2002, 64, 1019-1026. [CrossRef]

63. Pegg, A.E. Spermidine/spermine-N1-acetyltransferase: A key metabolic regulator. Am. J. Physiol. Endocrinol. Metab. 2008, 294, E995-E1010. [CrossRef] [PubMed]

64. Polticelli, F.; Salvi, D.; Mariottini, P.; Amendola, R.; Cervelli, M. Molecular evolution of the polyamine oxidase gene family in Metazoa. BMC Evol. Biol. 2012, 12,1-14. [CrossRef]

65. Jell, J.; Merali, S.; Hensen, M.L.; Mazurchuk, R.; Spernyak, J.A.; Diegelman, P.; Kisiel, N.D.; Barrero, C.; Deeb, K.K.; Alhonen, L.; et al. Genetically altered expression of spermidine/spermine N1- acetyltransferase affects fat metabolism in mice via acetyl-CoA J. Biol. Chem. 2007, 282, 8404-8413. [CrossRef] [PubMed]

66. Niiranen, K.; Keinänen, T.A.; Pirinen, E.; Heikkinen, S.; Tusa, M.; Fatrai, S.; Suppola, S.; Pietilä, M.; Uimari, A.; Laakso, M.; et al. Mice with targeted disruption of spermidine/spermine N 1 -acetyltransferase gene maintain nearly normal tissue polyamine homeostasis but show signs of insulin resistance upon aging. J. Cell. Mol. Med. 2006, 10, 815-827. [CrossRef]

67. Takao, K.; Shibata, S.; Ozawa, T.; Wada, M.; Sugitia, Y.; Samejima, K.; Shirahata, A. A conceptual model of the polyamine binding site of N 1- acetylpolyamine oxidase developed from a study of polyamine derivatives. Amino Acids. 2009, 47, 925-935. [CrossRef]

68. Ikeguchi, Y.; Bewley, M.C.; Pegg, A.E. Aminopropyltransferases: Function, structure and genetics. J. Biochem. 2006, 139, 161-169. [CrossRef]

69. Cervelli, M.; Amendola, R.; Polticelli, F.; Mariottini, P. Spermine oxidase: Ten years after. Amino Acids. 2012, 42, 441-450. [CrossRef] [PubMed]

70. Lüersen, K. Leishmania major thialysine $\mathrm{N} \varepsilon$-acetyltransferase: Identification of amino acid residues crucial for substrate binding. FEBS Lett. 2005, 579, 5347-5352. [CrossRef]

71. Li, C.H.; Ohn, T.; Ivanov, P.; Tisdale, S.; Anderson, P. eIF5A promotes translation elongation, polysome disassembly and stress granule assembly. PLoS ONE 2010, 5, e9942. [CrossRef]

72. Saini, P.; Eyler, D.E.; Green, R.; Dever, T.E. Hypusine-containing protein eIF5A promotes translation elongation. Nature 2009, 459, 118-121. [CrossRef] [PubMed]

73. Chawla, B.; Jhingran, A.; Singh, S.; Tyagi, N.; Park, M.H.H.; Srinivasan, N.; Roberts, S.C.C.; Madhubala, R. Identification and characterization of a novel deoxyhypusine synthase in Leishmania donovani. J. Biol. Chem. 2010, 285, 453-463. [CrossRef]

74. Diotallevi, M.; Checconi, P.; Palamara, A.T.T.; Celestino, I.; Coppo, L.; Holmgren, A.; Abbas, K.; Peyrot, F.; Mengozzi, M.; Ghezzi, P. Glutathione fine-tunes the innate immune response toward antiviral pathways in a macrophage cell line independently of its antioxidant properties. Front. Immunol. 2017, 8, 1239. [CrossRef] [PubMed]

75. Ribas, V.; García-Ruiz, C.; Fernández-Checa, J.C. Glutathione and mitochondria. Front. Pharmacol. 2014, 5, 151. [CrossRef] 
76. Carter, K.C.; Sundar, S.; Spickett, C.; Pereira, O.C.; Mullen, A.B. The in vivo susceptibility of Leishmania donovani to sodium stibogluconate is drug specific and can be reversed by inhibiting glutathione biosynthesis. Antimicrob. Agents Chemother. 2003, 47, 1529-1535. [CrossRef] [PubMed]

77. Koch, O.; Cappel, D.; Nocker, M.; Jäger, T.; Flohé, L.; Sotriffer, C.A.; Selzer, P.M. Molecular dynamics reveal binding mode of glutathionylspermidine by trypanothione synthetase. PLoS ONE 2013, 8, e56788. [CrossRef]

78. Fonseca, M.S.; Comini, M.A.; Resende, B.V.; Santi, A.M.M.; Zoboli, A.P.; Moreira, D.S.; Murta, S.M.F. Ornithine decarboxylase or gamma-glutamylcysteine synthetase overexpression protects Leishmania (Vianna) guyanensis against antimony. Exp. Parasitol. 2017, 175, 36-43. [CrossRef]

79. Saudagar, P.; Dubey, V.K. Cloning, expression, characterization, and inhibition studies on Trypanothione Synthetase, a drug target enzyme, from Leishmania donovani. Biol. Chem. 2011, 392, 1113-1122. [CrossRef] [PubMed]

80. Tran, A.N.; Andersson, B.; Pettersson, U.; Åslund, L. Trypanothione synthetase locus in Trypanosoma cruzi CL Brener strain shows an extensive allelic divergence. Acta Trop. 2003, 87, 269-278. [CrossRef]

81. Comini, M.; Menge, U.; Flohé, L. Biosynthesis of trypanothione in Trypanosoma brucei brucei. Biol. Chem. 2003, 384, 653-656. [CrossRef]

82. Oza, S.L.; Wyllie, S.; Fairlamb, A.H. Mapping the functional synthetase domain of trypanothione synthetase from Leishmania major. Mol. Biochem. Parasitol. 2006, 149, 117-120. [CrossRef] [PubMed]

83. Colotti, G.; Ilari, A. Polyamine metabolism in Leishmania: From arginine to trypanothione. Amino Acids. 2011, 40, 269-285. [CrossRef]

84. Karreth, F.A.A.; Tay, Y.; Perna, D.; Ala, U.; Tan, S.M.M.; Rust, A.G.G.; Denicola, G.; Webster, K.A.A.; Weiss, D.; Perez-Mancera, P.A.A.; et al. In vivo identification of tumor-suppressive PTEN ceRNAs in an oncogenic BRAF-induced mouse model of melanoma. Cells 2011, 147, 382-395. [CrossRef]

85. Mesías, A.C.; Sasoni, N.; Arias, D.G.; Brandán, C.P.; Orban, O.C.F.; Kunick, C.; Robello, C.; Comini, M.A.; Garg, N.J.; Zago, M.P. Trypanothione synthetase confers growth, survival advantage and resistance to anti-protozoal drugs in Trypanosoma cruzi. Free Radic. Biol. Med. 2019, 130, 23-34. [CrossRef] [PubMed]

86. Saudagar, P.; Saha, P.; Saikia, A.K.; Dubey, V.K. Molecular mechanism underlying antileishmanial effect of oxabicyclo[3.3.1]nonanones: Inhibition of key redox enzymes of the pathogen. Eur. J. Pharm. Biopharm. 2013, 85, 569-577. [CrossRef] [PubMed]

87. Irigoín, F.; Inada, N.M.; Fernandes, M.P.; Piacenza, L.; Gadelha, F.R.; Vercesi, A.E.; Radi, R. Mitochondrial calcium overload triggers complement-dependent superoxide-mediated programmed cell death in Trypanosoma cruzi. Biochem. J. 2009, 418, 595-604. [CrossRef] [PubMed]

88. Mesías, A.C.; Garg, N.J.; Zago, M.P. Redox balance keepers and possible cell functions managed by redox homeostasis in trypanosoma cruzi, front. Cell. Infect. Microbiol. 2019, 9, 435. [CrossRef] [PubMed]

89. Viola, A.; Munari, F.; Sánchez-Rodríguez, R.; Scolaro, T.; Castegna, A. The metabolic signature of macrophage responses. Front. Immunol. 2019, 10, 1462. [CrossRef]

90. Richardson, J.L.; Nett, I.R.E.; Jones, D.C.; Abdille, M.H.; Gilbert, I.H.; Fairlamb, A.H. Improved tricyclic inhibitors of trypanothione reductase by screening and chemical synthesis. Chem. Med. Chem. 2009, 4, 1333. [CrossRef]

91. Battelli, M.G.; Polito, L.; Bortolotti, M.; Bolognesi, A. Xanthine oxidoreductase-derived reactive species: Physiological and pathological effects. Oxid. Med. Cell. Longev. 2016, 3227579. [CrossRef] [PubMed]

92. Battelli, M.G.; Polito, L.; Bortolotti, M.; Bolognesi, A. Xanthine oxidoreductase in drug metabolism: Beyond a role as a detoxifying enzyme. Curr. Med. Chem. 2016, 35, 4027-4036. [CrossRef] [PubMed] 